\title{
Looking Beyond the Bridge: The Effect of Temporary Agency Employment on Labor Market Outcomes ${ }^{\circ}$
}

\author{
Elke J. Jahn ${ }^{+}$and Michael Rosholm*
}

November 2010

\begin{abstract}
We perform a comprehensive analysis of the stepping-stone effect of temporary agency employment on unemployed workers. Using the timing-of-events approach, we investigate not only whether agency employment is a bridge into regular employment but also its effect on post-unemployment wages and job stability for unemployed Danish workers. We find evidence of large positive treatment effects, particularly for immigrants and for individuals considered less employable. Our results show that agency employment is even more effective in tight labor markets, where firms use agency employment primarily to screen potential candidates for permanent posts. Network effects, however, do not play a large role for the stepping stone effect. Finally, our results suggest that agency employment may improve subsequent match quality in terms of wages.
\end{abstract}

Key words: temporary agency employment, stepping stone, employment stability, wages

JEL-Code: C41, J64, J30, J40

IAB Nürnberg, Aarhus School of Business, Aarhus University, and IZA Bonn, Elke.Jahn@iab.de.

* Aarhus School of Business, Aarhus University and IZA Bonn, rom@asb.dk

- The authors are grateful to Bernd Fitzenberger, Barbara Hofmann, Anton Nivorozhkin, Gesine Stephan, the participants of the CIM workshop in Aarhus, August 2009, the ZEW workshop on Flexibility in Heterogeneous Labour Markets in Mannheim, March 2010, the participants of the Annual Conference of the Applied Economic Association, April 2010 in Rome, the European Economic Association, August 2010, the seminar of the economics department at Aarhus University, September 2010, the Jahrestagung des Vereins für Socialpolitik, September 2010 in Kiel and the seminar of the economics departments in Mainz and Regensburg, November 2010 who provided valuable comments. The authors gratefully acknowledge financial support from Danish Social Science Research Council. 


\section{Introduction}

In this paper, we perform a comprehensive analysis of the stepping-stone effects of temporary agency employment on unemployed workers in Denmark in the period 1997-2006. Using the "timing-of-events" approach, we investigate whether agency employment generally acts as a bridge to regular employment, we look for heterogeneous effects of temporary agency jobs, and we analyse the cylical pattern of these effects. Moreover, we investigate how the treatment dose affect our results, and how temporary agency employment affects post-unemployment job quality as measured by wages and job stability.

The question whether temporary agency employment is a springboard into regular employment has become increasingly important since temporary agency employment has increased in most European countries during the past decade: in 2008, temporary agencies employed about 2 percent of the EU working population (CIETT 2010). Until recently, however, Denmark has been the exception, with an almost nonexistent temporary help sector. This has changed fundamentally. Although the temporary help sector is still small compared to the European average, it is far from being a negligible source of labor turnover and net employment growth today. In the past five years, the sector has increased almost fourfold, accounting for 1.7 percent of the total workforce in 2007 (Windelin and Hansen 2007). This marked increase comes as something of a surprise since the Danish labor market is relatively flexible and employment protection is considered very low. Moreover, until late 2008, the Danish unemployment rate was low and the labor market was considered to be tight. Since temporary agency jobs in Denmark usually provide less social benefits than other jobs do, one might surmise that workers had no incentive to take temporary agency jobs, such that the labor supply side may have rationed the market for temporary help services. However, the rapid growth of this sector may be the result of the intensified activation policies of the Danish public employment service. Pedersen et al. (2003) and Oxford Research (2003) present evidence that the unemployed are increasingly seeking and accepting jobs with temporary agencies as a route back into regular employment.

As in other European countries, there are concerns in Denmark whether temporary agency work traps workers in poor-quality jobs, or whether it might act as a bridge into regular employment - especially for individuals otherwise at risk of marginalization.

The theoretical impact of agency employment on the employment outcomes of the unemployed is not clear a priori. On the one hand, temporary work may improve workers' human capital and also provide them with labor market contacts that can later lead to stable employ- 
ment (e.g., Houseman et al. 2003, Jahn \& Ochel 2007). ${ }^{1}$ In this case, temporary agencies may reduce the time job-seekers spend looking for a new job and may facilitate rapid entry into regular employment. This holds the more if client firms use temporary staffing arrangements to screen workers to fill open posts.

On the other hand, it can be argued that any human capital effects arising from temp work cannot be strong due to the primarily short-term, low-skilled nature of temp jobs, which are often below the worker's qualifications (Segal \& Sullivan 1997). These jobs may even be dead-ends since firms may not plan to fill these jobs permanently, thus limiting the temp worker's regular employment prospects (Heinrich et al. 2005). Consequently, temporary agency work might not provide significant opportunities to develop productive job search networks, and it may even crowd out direct job search, inhibiting longer-term labor market advancement. Which hypothesis holds remains an open empirical question (see Section 2).

Our study contributes to the literature in several ways. First, we take a comprehensive look at the stepping-stone effect of temporary agency employment in Denmark for the period 1997-2006. Second, we take into account the different possible motivations for unemployed people to work as a temp. Although the majority of job-seekers probably accept temp work to avoid or escape unemployment, there may be also unemployed job-seekers who choose temporary agency employment as a career choice, to obtain or prolong eligibility for unemployment benefits, or to combine family responsibilities with labor market participation (CIETT 2002). Since the motivation to pursue temp work is usually not observable, it is important to separate the treatment effects from time-invariant unobserved variables affecting both the selection into temporary agency employment and the transition out of unemployment. The timing-of-events approach developed by Abbring \& Van den Berg (2003) is ideal for taking selection based on observed and unobserved heterogeneity into account. To the best of our knowledge, this is the first study employing and extending this approach to model the intreatment effect and post-treatment effect of taking a temporary agency job during a phase of unemployment. $^{2}$

In tight labor markets, companies have more job openings, fewer qualified job applicants, and they may find it too costly to assess the productivity of the workers still in the pool of unemployed job-seekers. As temp agencies face lower hiring and firing costs than conven-

1 To ease readability, we sometimes use the terms "temp job" and "agency work" interchangeably with "temporary agency employment".

2 De Graaf-Zijl et al. (2010) investigate, within the same framework, whether temporary employment acts as a stepping stone into regular employment in the Netherlands. Gagliarducci (2005) does the same for Italy and Göbel \& Verhofstadt (2008) for Belgium, focusing on school leavers. However, none of these studies have been able to distinguish between temporary agency employment and direct-hire temporary employment. 
tional direct-hire employers do, they may choose to hire individuals, who would otherwise have difficulties finding regular employment. By this means, job-seekers can overcome the negative stigma associated with an extended unemployment period or certain educational or cultural backgrounds (e.g., Autor \& Houseman 2002, Jahn 2010a, Katz \& Krueger 1999). In order to investigate whether agency employment might work particularly well for some subgroups, we contribute to the literature, third, by estimating heterogeneous treatment effects.

It is a well-known fact that the demand for temp workers moves pro-cyclically. If the labor market tightens, client firms use temp agencies not only to screen potential candidates to fill vacancies but also to buffer core workers in case demand declines in an economic downturn (e.g., Abraham 1990, Booth et al. 2002). Consequently, agency workers are the first to be laid off in a recession. We therefore test, fourth, whether the stepping-stone effect depends on the tightness of the labor market.

Fifth, this is the first paper to shed light on the human capital hypothesis outlined above by investigating whether conditioning on the number and cumulative duration of past treatments during the current unemployment spell affects the results. If workers can indeed increase their human capital or build up productive job search networks during different assignments, we would expect that the hazard rate to non-temp jobs would increase with treatment intensity.

Sixth, we are interested not only in the causal effect on the job-finding rate for regular jobs, but also in the post-unemployment job and employment duration and in post-unemployment wages, i.e., whether temporary agency employment might improve several aspects of subsequent employment quality.

Finally, we contribute to the methodological refinement of the timing-of-events approach by modeling not only the time until treatment as it is usually done in order to take into account the endogeneity of the treatment decision, but also the duration of the treatment itself, thus taking into account the potential endogeneity of the treatment dose or duration.

We find a fairly high in-treatment effect (i.e., while holding a temp job) increasing the transition rate into non-temp employment by 88 percent for men and by about 97 percent for women. However, we find no evidence for a post-treatment effect for men and a negative post-treatment effect for women. Moreover, our results indicate that both the in-treatment and the post-treatment effects are stronger in regions and periods with tight labor markets. In addition, we find that temporary agency employment has particularly large impacts on male first generation non-western immigrants, and on all female immigrant groups as well as their descendants. Recipients of unemployment assistance gain both in terms of the in- and posttreatment effects. 
We provide also some evidence that the intensity of treatment affects the likelihood of finding a regular job; a larger number of weeks in treatment during the present unemployment spell increases the job-finding rate during the current treatment. However, we find no support for the network hypothesis. On the contrary, having received more than two treatments seems to harm the unemployed, indicating that stigma effects might play a role.

Finally, we show that in Denmark, agency employment is a means to improve the quality of post-unemployment jobs, in terms of subsequent hourly wages.

The results of this paper may be of interest to policy makers, since temporary agency employment shows potential as an instrument of active labor market policy. In particular, many instruments used in labor market policy have been shown to have large lock-in effects (that is, negative in-treatment effects), implying that participants are temporarily harmed by them. Temp employment has the opposite effect, namely, it increases the exit rate into permanent employment while in treatment.

Some US states have already experimented with such instruments. While some researchers have advocated the involvement of temporary agencies in job placement programs (Lane et al. 2003, Andersson et al. 2009), the study by Autor \& Houseman (2005) argues that such a policy recommendation may be premature. Our results may be taken as an indication that temporary agency employment could be used successfully as an instrument of active labor market policy if targeted at the right treatment groups at the right time.

The paper is organized as follows. A brief review of the empirical literature is provided in Section 2. Section 3 highlights key facts about the temporary help sector in Denmark. Section 4 presents the estimation strategy. Section 5 introduces the data set and presents the main descriptive statistics. In Section 6, we discuss the results, and in Section 7 we draw conclusions and provide a policy discussion.

\section{Empirical Evidence}

As outlined in the introduction, the theoretical impact of agency employment on postunemployment outcomes is not clear-cut. As a result, a growing literature has emerged, attempting to identify the effects of agency employment on subsequent labor market outcomes. Yet even the empirical evidence is contradictory. No evidence of temporary work acting as a springboard into regular employment has been found so far for Germany (Kvasnicka 2009) or Spain (Amuedo-Dorantes et al. 2008). Malo \& Muñoz-Bullón (2008) show that temp work tends primarily to affect married women, and García-Pérez \& Muñoz-Bullón (2005) show that temp work only affects young, short-term unemployed workers in Spain. In Italy, the effect on labor market outcomes depends on the region in question (Ichino et al. 2008). In general, it 
seems that rigid European labor market institutions do not facilitate successful transitions from temp work into permanent work. The American evidence is somewhat more promising. ${ }^{3}$ However, due to the different institutional background there, most US studies concentrate on the earnings and employment stability of low-wage earners or recipients of income subsidies who enter the temporary help service sector. Overall, most studies suggest that temporary agency employment at least does not have any long-run negative effects on the outcomes of temp workers.

To identify the causal effects of agency employment on the likelihood of obtaining a permanent job, the vast majority of studies use variants of the conditional independence assumption (CIA), and concerns remain about selection on variables that are unobservable (Autor 2009). The debate on whether the CIA may be violated has intensified since the study by Autor \& Houseman (2005). Using a quasi-experimental setting, they show that moving welfareto-work program participants into temporary help jobs increases their short-term earnings. However, these effects are offset by lower earnings, less frequent employment, and higher welfare recidivism over the subsequent seven quarters.

Our study contributes to this debate by employing and extending the timing-of-events approach to model the causal effect of temporary agency employment on various labor market outcomes. The advantage of this approach is that it exploits the random variation in the timing of the treatment to separate the time-varying treatment effects from the (assumed) timeinvariant unobserved variables affecting the selection into temporary agency employment, the exit from temp jobs, and the transition into regular employment.

\section{Temporary Agency Employment in Denmark}

Until 1990, the Danish temporary help sector was subject to comprehensive regulation. Since 1990, more or less all regulations on establishing and operating a temporary employment agency have been removed. Consequently, there is free market access for all agencies except those serving the health care and transportation sectors. In the latter two cases, agencies need authorization to operate and are required to employ staff with a medical background or a vocational degree in the transport sector, respectively.

Collective bargaining at the industry, agency, and user-firm level also plays an important role in determining the conditions for temporary agency employment in Denmark, often re-

3 For example, Lane et al. (2003), Andersson et al. (2005, 2009), Hamersma \& Heinrich (2008) and Heinrich et al. (2009). The results of these studies are discussed thoroughly in Autor (2009). 
placing legal regulations. ${ }^{4}$ About 80 percent of Danish temp workers are members of unemployment insurance funds, which are operated by unions. Generally, standard labor law applies when hiring a temp worker. Nevertheless, agency workers who are employed for less than six to nine months at the same job are not protected by the act governing the legal relationship between employer and employee (Funtionærloven) and are usually not eligible for employment benefits such as maternity benefits, vacation pay, leave to care for a sick child, or disability pensions, or the right to at least one month's notice of termination, which may adversely affect agency workers on shorter contracts.

Until recently, the temporary help sector was very small in Denmark. Temporary agency workers were mainly used to adapt the size of the workforce to fluctuations in demand and to temporarily replace permanent staff members who were on leave or sick. On the labor supply side, a lack of employment and income security, and frequent changes of working conditions, were among the reasons why most workers did not consider agency jobs to be attractive when alternative job offers were available.

This has changed dramatically. Since 1997, the temporary help sector has undergone impressive growth. The share of temporary agency workers (full-time equivalent) increased more than five-fold, from 0.2 percent in 1997 to 1.1 percent in 2007 . This may be only the bottom line. If the share of temp workers is calculated as the number of persons who accepted a temp job, it totaled 1.7 percent of the workforce in 2007 (Windelin and Hansen 2007).

Despite the fact that large agencies dominate the temporary help market, the number of registered agencies has increased considerably, from 305 in 2005 to 623 in 2007 (Mølgaard and Hansen 2008). Until 2002, the health care sector dominated the temp industry, but since then, it has been overtaken by the manufacturing, construction, and transport sectors (KudskIversen \& Andersen 2006). In 2007, the health care sector was responsible for 32 percent of total turnover in the temp industry; the industrial sector was responsible for 35 percent and the transport sector for 10 percent (Statistics Denmark 2009). As agency jobs have opened up in blue-collar occupations, the temporary help industry has become an increasingly important employer of less-skilled workers.

There are several reasons responsible for the spectacular growth of the Danish temporary help service sector: First, the temporary help sector may serve as a stepping stone into the Danish labor market, not only for the unemployed but also for groups such as East European immigrants: 13 percent of the "work and stay" permits issued since 2004 have been granted to East Europeans hired by temporary agencies (Andersen 2007). The growing pool of immi-

4 A comprehensive and detailed description of the system of collective bargaining in the Danish temporary help service sector can be found in Arrowsmith (2008). 
grants available for temporary agency employment may have attracted employers' interest and demand in many sectors.

Second, as a consequence of the tight labor market in Denmark, client firms often faced bottlenecks when recruiting new workers. In response, temporary agencies specialized in identifying agency workers' skills and matching them with the staffing needs of firms. This offers employers the advantage of reducing the effective hiring costs associated with hiring new employees, and also enables them to screen workers for direct-hire positions and improve subsequent match quality. The screening device hypothesis may play a particularly important role on the Danish labor market: during our observation period, the pool of unemployed comprised many workers who would have difficulties to find employment through normal search channels.

Third, temporary agency work is attractive to workers in the health care sector. According to anecdotal evidence, agency employment allows workers in the public health sector - especially nurses and doctors - not only to better determine their own working hours but also to bargain for higher wages. Jahn (2010b) shows that nurses employed through temp agencies indeed receive considerably higher wages than nurses employed in non-temp firms.

Finally, recent research has refuted the assumption that most Danish temporary agency workers are accepting temp jobs by choice. According to Pedersen et al. (2003) and Oxford Research (2003), most of the temp workers interviewed in their field studies had chosen this form of employment out of financial need or a desire to escape unemployment. These findings, in combination with the increased share of low-skilled workers in this sector, have fueled the debate on whether temporary agency work improves or worsens unemployed people's labor market chances.

\section{Econometric Strategy}

The aim of this study is to investigate whether taking up a temporary agency job may be a bridge from unemployment to employment. Hence, our population of interest is individuals who have lost their jobs or who have otherwise become unemployed. Thus, we sample workers at the point in time when they enter unemployment and analyze how long it takes them to find non-temp work and whether having worked for a temp agency while they were unemployed accelerates this process. The duration modeled is therefore the time from becoming unemployed to finding a non-temp job. The take-up of temporary work during this period is considered the treatment, the effect of which we want to estimate.

As unemployed workers do not take up agency jobs at random, we have to distinguish the causal effects of temporary agency employment from selection effects. As outlined in Section 
2, most European studies use the Conditional Independence Assumption (CIA) when analyzing the stepping stone effect of temporary agency employment. However, if there are unobserved variables influencing the selection process as well as the potential outcomes, the CIA approach will result in biased estimates. Albeit the data set at hand is quite detailed, it may be questionable whether the CIA holds as the motivation why unemployed workers would take up an agency job is a priori not obvious, as the discussion above shows.

An alternative econometric approach may therefore be a duration model, analyzing the time from inflow into unemployment until non-temp employment is obtained, taking into account the endogenous choice of workers to accept agency work. Such an analysis aims at estimating the causal effect of working in the temporary help sector on the duration of unemployment, or alternatively, on the exit rate from unemployment to regular employment. This is done by exploiting the timing-of-events approach formalized by Abbring and Van den Berg (2003). Exploiting random variation in the observed moment of transition from (full-time) unemployment to temporary agency employment, this approach is ideal for separating selection effects from causal effects.

\subsection{The Timing-of-Events Approach}

We consider being employed by a temporary agency during a spell of unemployment to be the treatment, and we then want to estimate the effect of this treatment on the exit rate from unemployment to employment, both during and after the treatment. Let $T_{u}$ be a continuous random variable measuring the time from becoming unemployed to being hired into non-temp employment. Data on $T_{u}$ are censored for those who remained unemployed until the last week of the observation period and for those making transitions out of the labor force. The hazard rate into a non-temp job is assumed to be a Mixed Proportional Hazard (MPH):

$$
\theta_{u}\left(t \mid x, d_{1}(t), d_{2}(t), v_{u}\right)=\lambda_{u}(t) \exp \left[x \beta_{u}+d_{1}(t) \gamma_{1}+d_{2}(t) \gamma_{2}+v_{u}\right]
$$

The hazard function is specified as the product of a baseline hazard, $\lambda_{u}(t)$, depending on the elapsed unemployment duration, and a scaling function depending on observed variables, $x$, unobserved heterogeneity that accounts for possible selectivity in the exit process $v_{u}$, and two time-varying indicators, one for being in treatment, $d_{1}(t)$ (i.e., being employed by a temp agency at time $t$ ), and one for having been in treatment earlier, $d_{2}(t)$ (i.e., having been a temp during the current unemployment spell before $t$ but not a temp at $t$ ). The coefficients $\gamma_{1}$ and $\gamma_{2}$ thus capture the in-treatment and post-treatment effects of temp jobs on the hazard rate into non-temp employment, respectively. 
In the case of active labor market programs, one often observes that $\gamma_{1}$ is negative, i.e., that there is a lock-in effect. However, in the case of temporary agency employment, the sign of $\gamma_{1}$ is not obvious. On the one hand, while on assignment, the temp worker has less time to search for a job outside the temp sector. On the other hand, it is well known that client firms also use temporary agency employment as a screening device. This may be particularly true in Denmark, where the labor market is considered to have been tight during most of the observation period. In this case, agency workers who possess the relevant skills may receive an offer for a permanent job faster than comparable individuals conducting their job search from open unemployment.

If $\gamma_{2}$ is positive, it means that the skills or the network obtained during a temp job increases the subsequent chances of finding non-temp employment. On the other hand, a negative effect would normally be interpreted as some type of stigma. If temporary agency employment is to act as a bridge into non-temp employment, then either $\gamma_{1}$ or $\gamma_{2}$ (or both) should be positive.

We model the baseline hazard using a flexible, piecewise-constant specification:

$$
\lambda_{u}(t)=\exp \left[\sum_{l}\left(\lambda_{u, l} I_{l}(t)\right)\right]
$$

where $l=0, \ldots, 11$ is a subscript for the (11) time intervals measured in weeks and $I_{l}(t)$ are time-varying indicator variables for elapsed duration $t$. We split the analysis period during the first six months into monthly intervals. From the seventh month on, we split the time axis into quarterly intervals up to two years, after which the exit rate is assumed to be constant.

In order to allow an interpretation of $\gamma_{1}$ and $\gamma_{2}$ as causal effects, we have to take into account the potential endogeneity of temporary agency employment, i.e. the decision to take up a temp job while being unemployed. Let $T_{p}$ denote the time from becoming unemployed until the person finds a temporary agency job. Note that we consider temp periods to be part of the unemployment spell, hence, if $T_{p}$ is observed, it is shorter than $T_{u}$. Following the notation used above and specifying once again an MPH function, the transition rate into temporary agency jobs is specified as:

$$
\theta_{p}\left(t \mid x, v_{p}\right)=\lambda_{p}(t) \exp \left[x \beta_{p}+v_{p}\right]
$$

The unobserved random variables, $v_{u}, v_{p}$, are allowed to be correlated, which implies a correction for the potential endogeneity of the treatment status. 
Let $C_{i}$ be a non-censoring indicator that takes the value of 1 if spell $i$ was completed by a transition into a non-temp job before the end of the observation period, and zero otherwise. The likelihood function for individual $j$ with $N$ unemployment spells is specified as

$$
L\left(v_{u}, v_{p}\right)=\prod_{i=1}^{N} L_{i}\left(v_{u}, v_{p}\right)
$$

where

$$
\begin{aligned}
& L_{i}\left(v_{u}, v_{p}\right) \\
& =\theta_{p}\left[t_{p i} \mid x_{i}, v_{p}\right]^{I\left[t_{p i}<t_{u i}\right]} \theta_{u}\left[t_{u i} \mid x_{i}, d_{1}\left(t_{u i}\right), d_{2}\left(t_{u i}\right), v_{u}\right]^{C_{i}} \\
& \times \exp \left\{-\int_{0}^{t_{p i}} \theta_{p}\left[s \mid x_{i}, v_{p}\right] d s-\int_{0}^{t_{u i}} \theta_{u}\left[r \mid x_{i}, d_{1}(t), d_{2}(t), v_{u}\right] r t\right\}
\end{aligned}
$$

However, there is an additional potential source of endogeneity, which might be important when analyzing the stepping stone effect of agency employment; the endogeneity of the duration of the temp job itself. To check whether the selection out of temp employment and back into open unemployment affects our results, we refine the timing-of-events approach by modeling explicitly the treatment duration.

Let $T_{d}$ denote the duration of the temp job, that is, the treatment dose. The temp job may end by a transition directly into permanent employment, which is already modeled in equation (1) above. If this occurs, the treatment duration $T_{d}$ is treated as censored. Hence, $T_{d}$ measures the (potentially latent) time until a transition into open unemployment occurs. The treatment duration is modeled in the following way:

$$
\theta_{d}\left(t \mid x, t_{p}, z, v_{d}\right)=\lambda_{d}(t) \exp \left[x \beta_{d}+f\left(t_{p}\right)+z \gamma+v_{d}\right]
$$

Note that we condition on the time taken until the treatment has begun. This is included as a step function, using the same intervals as those used for the baseline hazard function (except we collapse the last 5 intervals, since there are very few temp jobs lasting longer than 52 weeks). As further controls, $z$, we included the wage received during the temp job, the number of previous treatments, as well as the accumulated number of weeks in temp jobs before the current temp spell. In this case the likelihood function (3) changes to:

$$
L\left(v_{u}, v_{p}, v_{d}\right)=\prod_{i=1}^{N} L_{i}\left(v_{u}, v_{p}, v_{d}\right)
$$

where 


$$
\begin{aligned}
& L_{i}\left(v_{u}, v_{p}, v_{d}\right) \\
& =\theta_{p}\left[t_{p i} \mid x_{i}, v_{p}\right]^{I\left[t_{p i}<t_{u i}\right]} \theta_{d}\left[t_{d i} \mid x_{i}, t_{p}, z, v_{d}\right]^{I\left[t_{p i}+t_{d i}<t_{u i}\right]} \theta_{u}\left[t_{u i} \mid x_{i}, d_{1}\left(t_{u i}\right), d_{2}\left(t_{u i}\right), v_{u}\right]^{C_{i}} \\
& \times \exp \left\{-\int_{0}^{t_{p i}} \theta_{p}\left[s \mid x_{i}, v_{p}\right] d s-\int_{0}^{t_{d i}} \theta_{d}\left[t \mid x_{i}, t_{p}, z, v_{d}\right] d t-\int_{0}^{t_{u i}} \theta_{u}\left[r \mid x_{i}, d_{1}(t), d_{2}(t), v_{u}\right] d r\right\}
\end{aligned}
$$

Note that in both cases random variation in the timing of the beginning of the treatment identifies the causal effect of the treatment under the assumption that unobserved characteristics are time-invariant and that there is no anticipation of treatment. ${ }^{5}$ The distribution of unobserved variables is approximated non-parametrically by a bivariate (or in the extended model a trivariate) discrete distribution with M mass points (Heckman \& Singer 1984 and Gaure et al. 2007). Moreover, due to the random variation in the timing of treatment, no exclusion restriction is necessary to identify the parameters of this model non-parametrically. The only assumption necessary, beyond the assumption of mixed proportionally hazards, is one of nonanticipation; that is, the individual is not supposed to know in advance the exact starting date of the agency job, only its probability distribution. This assumption is crucial to rule out changes in behavior before the actual treatment takes place. As long as the individual does not know the exact starting date too long in advance, this is generally not perceived as a problem. In the case of temporary agency jobs, where workers are often called the same morning that the job begins, this is hardly a large problem.

In all estimations performed, we first estimate the model without unobserved heterogeneity, and then we proceed by adding additional points of support to the distribution of unobservables until the likelihood does not improve enough to satisfy the Akaike Information Criterion. This procedure typically results in about six support points in the final estimation. Parameter estimates of treatment effects typically start to stabilize after the third or fourth support point has been added.

\subsection{Modeling Effects for Sub-Groups}

We estimate effects for different sub-groups by allowing the effects to depend on the observable characteristics, and we assume that all heterogeneity is captured in this way. Conditional on observables, the effects are assumed to be homogenous, and hence, we do not have to dis-

\footnotetext{
5 With multi-spell data, identification does not depend completely on the proportionality assumption when we assume the unobserved heterogeneity term to be constant over time for each individual (Abbring \& Van den Berg 2003). Furthermore, the proportionality assumption is not needed for identification provided that we observe a sufficient amount of variation in covariates over time and across observations (Brinch 2007, Gaure et al. 2007).
} 
tinguish between the average treatment effect on the treated and the average treatment effect as long as we condition on observable characteristics (Heckman et al. 1999).

To estimate heterogeneous effects of temporary agency employment, we augment the set of characteristics by including interaction terms between a subset of the characteristics, $x^{s}$, and the two treatment indicators $d_{1}(t)$ and $d_{2}(t)$. This implies that the effect of agency employment is allowed to vary with these characteristics. Apart from a larger set of parameters, the estimation procedure is as before, and the hazard function out of unemployment to employment can be written as

$$
\theta_{u}\left(t \mid x, d_{1}(t), d_{2}(t), v_{u}\right)=\lambda_{u}(t) \exp \left[x \beta_{u}+\left(1 x^{s}\right) d_{1}(t) \gamma_{1}+\left(1 x^{s}\right) d_{2}(t) \gamma_{2}+v_{u}\right]
$$

Where $\left(1 x^{S}\right)$ is a $(K+1)$ vector of characteristics, and $\gamma_{1}$ is a $(K+1)$ parameter vector, and similarly for $\gamma_{2}$.

Moreover, we test whether the treatment is more effective when labor markets are tight, as we have hypothesized. This is done by interacting the treatment dummies with the local unemployment rate.

Finally, we investigate how the treatment effects depend on the treatment intensity. We construct two measures of treatment intensity; the first is a time-varying variable, which measures, at elapsed duration $t$, the number of temp jobs held during the unemployment spell up until time $t$. The second variable is also time-varying, and it measures the accumulated number of weeks spent in treatment until time $t$.

\subsection{Modeling Post-Unemployment Outcomes}

In the next step, we extend the basic timing-of-events model by looking beyond the unemployment spell at some indicators of job quality. We want to investigate whether holding a temp job affects the hourly wages in the subsequent job and the duration of that job spell and employment spell, where an employment spell is defined as a sequence of non-interrupted job spells.

First, we follow Arni et al (2009) by modeling the post-treatment wage explicitly. However, contrary to them, we specify a log-normal distribution for the post-unemployment wage, that is,

$$
f\left(w \mid x, v_{w}\right)=\frac{1}{\sigma} \cdot \varphi\left(\frac{\ln w-x \beta_{w}-v_{w}}{\sigma}\right),
$$

where $\varphi($.$) denotes the pdf of the standard normal distribution. The reason for choosing$ the log-normal distribution for the wage equation is that it has been the conventional choice in the literature on wage equations. The parameters of this model are then estimated jointly with 
those of the model specified in (1), extending again the distribution of unobservables. The advantage of this specification is that we are able to present estimates of the size of the wage advantage or disadvantage compared to the control group as well.

Moreover, within the same framework we evaluate the effects of temporary agency employment on subsequent job and employment stability. First, we analyze the impact of temporary agency employment on the duration of the first non-temp job, starting immediately after unemployment exit. A job spell is defined as the number of consecutive weeks in employment with the same employer. Second, we perform the same analysis with respect to the employment stability, analyzing the duration of uninterrupted employment, which may consist of a sequence of job spells. Denote by $T_{j}$ and $T_{e}$ the job and employment duration, respectively. The hazard rate out of job or employment is also specified as an MPH:

$$
\theta_{i}\left(t \mid x, d_{1}, d_{2}, v_{i}\right)=\lambda_{i}(t) \exp \left[x \beta_{i}+d_{1} \gamma_{1 \mathrm{i}}+d_{2} \gamma_{2 \mathrm{i}}+v_{i}\right], \quad i=e, j
$$

Note that here the two treatment indicators $d_{1}$ and $d_{2}$ are time-invariant, since they measure whether the person made a transition into a non-temp job directly from a temp job $\left(d_{1}=\right.$ 1) or from open unemployment following a temp job $\left(d_{2}=1\right)$. Once again, the model of the likelihood function in section 4.1 is extended to include the contribution to the likelihood function from the job or employment duration model, that is, we jointly estimate employment (or job-) duration, unemployment duration, and the duration until a temp job (the treatment). Unobserved variables in all hazard rates are allowed to be correlated, as in the basic model.

\section{Data Sources and Descriptive Statistics}

Our empirical analysis is based on two rich sets of Danish register data. Our primary data set is an extract from a matched employer-employee data set, which contains weekly information on all persons aged 16 to 75 living in Denmark. The data set is compiled from a variety of sources maintained by Statistics Denmark. It records all transitions between employment, unemployment, participation in programs of active labor market policy, and being outside the labor force, and it also provides accurate information on the establishment in which the worker is employed and the hourly wages in the current job. To this data set, we match additional socio-economic information available from the Integrated Database for Labour Market Research (IDA), which is also maintained by Statistics Denmark. As the combined data set allows us to construct the (un-)employment careers of workers, which is exact to the week, it is especially suitable for performing duration analyses. Due to its administrative nature, the data set can be considered highly reliable. 
Nevertheless, the data set has one minor limitation: we can identify employment spells in temporary help agencies only by an industry classification code. This implies that temp workers cannot be distinguished from the permanent administrative staff of temporary employment agencies. However, we do not expect that this affects our estimations, since the absolute number of the permanent staff members in the data set is likely to be small, and we concentrate our analysis on temp workers who were unemployed before accepting the temp job. ${ }^{6}$

For the analysis, we use all individuals aged 16 to 60 who were employed by a temp agency at least once during an unemployment spell starting in the period 1997 to 2006, and a two percent random sample of all other individuals aged 16 to 60 starting an unemployment spell during the same period. There is also information available for the period 1994 to 1996, and this is used to construct the previous employment history of the job-seekers.

An unemployment spell is defined as a sequence of weeks during which a person receives either UI benefits, is in some type of active labor market policy program, or is employed at a temp agency. Thus, agency employment is treated as a part of the unemployment spell in order to enable the counterfactual analysis. Unemployment spells continuing until the end of the sample period are treated as independently right-censored observations (about 3.9 percent of all spells).

The dependent variable is the unemployment duration measured in weeks. The two explanatory variables of interest are the time-varying indicator of being employed as a temp worker, and the time-varying indicator of having been employed as a temp worker at a previous time during the current unemployment spell. We define the destination "regular employment" as non-temp employment and self-employment. ${ }^{7}$

In order to concentrate on workers who accept an agency job because of a lack of alternatives outside the sector, the following selection decisions are made. First, our treatment group only includes temp workers who received unemployment insurance benefits or unemployment assistance before entering temp employment. ${ }^{8}$ Second, we only include temp spells if the temporary agency job is the primary job. Third, unemployed job-seekers often try to escape unemployment by upgrading their education, but do temp work at the same time to augment their income. Since their motivation might not be primarily to find employment outside the

6 For Germany, Antoni and Jahn (2009) provide evidence that permanent agency staff members account for about 7 percent of the stock of all workers identified as temp workers via the industry classification code. In the inflow to temp jobs from unemployment, this ratio is likely to be considerably lower, since the staff of temp agencies obviously experience fewer transitions into and out of jobs than the temp workers themselves.

7 One might argue that self-employment (out of unemployment) is often as precarious as temporary agency jobs. We therefore estimated the model defining the destination only as salary or wage employment. The results are nearly identical to those reported in Table 1 and are available upon request.

8 This decision is also motivated by the fact that the model implemented cannot deal with selection at time zero. 
sector, we exclude all unemployment spells of individuals who are simultaneously attending formal education. Fourth, as mentioned earlier, there is some evidence that the reason for accepting a temp job in the health care sector may be driven mainly by income motives. Therefore, we exclude all individuals who are educated as nurses or as medical doctors.

Finally, we exclude individuals who hold top management positions, as it is likely that they belong to the permanent staff of the agency. For the same reason, we exclude temp workers with a temp spell lasting more than one year. After this sample selection, the sample consists of 75,630 individuals experiencing a total of 260,635 unemployment spells. ${ }^{9}$

We present all results separately by gender, as the kind of jobs vary considerably between these two groups. While men are mainly assigned to the construction and manufacturing sector, women are more likely to be found in the trade and service sector.

In addition, the following socio-demographic variables are used: age (5 categories), single or not, ethnic origin (5 groups), child in the household, child below age of 7 in the household, and a dummy variable that indicates whether the partner is employed. In addition, we have five educational variables, information on the UI fund (nine occupation/industry-related funds), and a dummy variable that indicates whether or not the worker is a member of a UI fund, non-membership implying that the worker receives unemployment assistance, which is considerably lower than UI benefits.

As a proxy for the human capital of the worker, we use the employment history of the past three years: previously employed (in the temporary help sector, self-employed, or in regular employment, the latter of which is the reference category), sick, or out of the labor force. Moreover, we control for the total fraction of time spent in employment during the past three years, the number of temp and regular jobs held, and the number of programs of active labor market policy that the worker attended during the past three years. Finally, we include dummies for the year and quarter of entry into the current unemployment spell as well as the regional unemployment rate (based on 14 counties). All controls, except for the two main explanatory variables, are measured at the beginning of the unemployment spell and will be treated as time-invariant regressors, which are fixed for each single spell but can vary over different spells for the same person.

\section{[Table 1 about here]}

Table 1 presents an overview of events and outcomes for the treated and the untreated group separated by gender. As there are only small differences between men and women, we report in the following the results for the pooled sample. The observations refer to unem-

9 Table B1 informs about the number of cases excluded for the above-mentioned reasons. All tables in Appendix $\mathrm{B}$ will be available to the interested reader online or upon request. 
ployment spells, not to individuals. Of the 260,635 unemployment spells, 25,436 involve at least one temporary agency work spell. Clearly, there are strong differences in the median duration of unemployment. Median search for a regular job lasts about 10 weeks for the untreated group and 33 weeks for individuals who experienced a temp spell during unemployment. The median (mean) time until first accepting an agency job is about 10 (21) weeks. The median (mean) duration of a temp spell is about 5 (9) weeks and the average number of separate temp spells (separated by unemployment) during a given unemployment spell is 1.6; 7,417 or about 29 percent of the unemployment spells of the treated group experienced more than one temp job during the unemployment spell. Table 1 also shows that 76 (79) percent of the male (female) treated group ultimately ended up in regular employment. This is only the case for 60 (65) percent of the comparison group.

The sample statistics reveal that there are only minor differences in terms of background characteristics between the treated and the untreated, see Table A1. Women are more likely to experience a temporary agency spell during unemployment and they are slightly older (36 years of age) than their male counterparts (33 years of age). The treated are on average about one year younger than the untreated, and are more often single (76 vs. 73 percent for men and 62 vs. 56 percent for women). Among the immigrants, only the first-generation non-western immigrants appear underrepresented among the treated. However, compared to the national average, immigrants are overrepresented in the pool of unemployed. During the observation period, the mean regional unemployment rate was about 5.9 (standard deviation 1.4). As a consequence of the tightness of the Danish labor market, the educational attainment of the unemployed is low. On average, 47 percent of workers do not have any vocational training or further education. Compared to the untreated, the treated group is slightly better qualified, indicating that some qualifications might be an advantage in finding even temp jobs. Finally, the share among the unemployed (treated or not) who are not eligible for unemployment benefits is rather high. About 29 percent of the male and 16 percent of the female unemployed received only unemployment assistance.

Regarding the previous employment history of the unemployed, the differences are more pronounced. The treated group held on average 0.8 temp jobs during the past three years before becoming unemployed, while the untreated held on average only 0.4 temp jobs. About 51 percent of the untreated were regularly employed previous to the unemployment spell, while this was only the case for 37 percent of the treatment group. ${ }^{10}$

10 Some of the individuals actually held a temp job before becoming unemployed, that is, they went from permanent employment or out of the labor force to temp employment and then into open unemployment. As the model does not allow for selection at time zero, in the estimations presented here unemployment begins with 


\section{Results}

\subsection{Empirical Hazards and Selection into Treatment}

Figure 1 shows, first, the Kaplan-Meier estimates of the transition rate from unemployment to temporary agency employment as a function of elapsed unemployment duration; second, the hazard rate from unemployment to regular employment for unemployed who did not hold a temp job during unemployment (the untreated); and third, the hazard rate to regular employment for the treated individuals. All durations are measured from the time of unemployment entry in weeks.

[Figure 1 about here]

The hazard rate to temporary employment measures the probability of entering temporary employment in the next week for those who are unemployed at the beginning of each week. As stated in Section 4, a key identifying assumption is that we observe some exogenous variation in the time until being treated. Figure 1 shows that there is indeed a great deal of variation in these durations. The hazard rate to agency employment for men starts at about 0.6 percent per week and decreases over the first year of unemployment to a level of around 0.2 percent. The hazard rate to agency employment for unemployed women starts at a slightly higher level (0.7 percent) and, similarly to the hazard rate for the men, decreases gradually during the first year of unemployment to 0.3 percent.

The hazard rates to regular employment for the untreated start at a level of 5 percent for men and 7 percent for women and gradually decrease thereafter. Interestingly, the hazard rate to employment jumps up after 6 months and again after one year for women. One reason may be that Denmark uses instruments of active labor market policy quite intensively. After one year (26 weeks for young workers and workers above 60), participation in active labor market programs becomes compulsory.

Finally, Figure 1 displays the hazard rates to employment for the treated unemployed. The exit rate for the treated starts, by construction, very low (since they have a treatment period before leaving unemployment), peaks at about 2 percent after 26 weeks of job search have elapsed, stays constant for another 6 months, and tapers off gradually to the original value of just 1 percent per week after 120 weeks of elapsed unemployment duration. Moreover, after six months, the exit rate for the treated lies well above the hazard rate for the non-treated. This pattern suggests that the dynamics of the job search process are important, as conditioning on

the open unemployment spell. However, as a robustness check, we also add these temp spells to the analysis by generating an artificial 0.1 -week period of open unemployment to the beginning of such unemployment periods. In addition, we estimated the model excluding those unemployment spells. It turns out that our results which are available upon request are robust to such changes. 
unemployment duration is obviously crucial when estimating treatment effects - the treated are found among those who did not find a regular job shortly after becoming unemployed. Moreover, it suggests that taking into account the dynamics of the selection process is important as well. It also implies that either there is a fairly strong treatment effect, or that the treated and untreated differ considerably in observable or unobservable ways.

Results of the selection equation (time until a temp job) and the main equation (time until ordinary employment) are shown in appendix Table A2 for the model with homogenous treatment effects and six support points. For the sake of brevity, we will not report these in any detail, but we will briefly mention the main patterns in the selection equation.

First of all, duration dependence in the selection equation is slightly hump-shaped, with a peak at 12-16 weeks for men and at 8-12 weeks for women. Young workers below the age of 24 have a much higher transition rate to temp jobs than older workers. Workers aged 45 or more have a considerably lower transition rate into temp jobs than those between 25 and 44 . Living with a working partner in the household (married or not) is associated with a higher probability of receiving treatment compared to all other family status categories. Women with children have a lower transition rate into treatment, especially if there is a child below seven years of age in the household.

The transition rate into temp jobs for non-western immigrants is considerably lower than for Danes and western immigrants. Moreover, we find that the least skilled workers, without any formal educational qualifications and unemployed with a master's degree or higher, are much less likely to take temp jobs than those with vocational or short academic education. Finally, the transition rate into temporary work increases with the fraction of time the person was employed during the past three years.

\subsection{Unobserved Heterogeneity and Treatment Effects}

In order to estimate homogenous treatment effects across individuals, we proceed as follows. We first estimate a basic duration model with flexible baseline, no unobserved heterogeneity, no selection, and only the two main explanatory variables (in-treatment and post-treatment). Second, we estimate the same model but adding the covariates described in Section 5. Third, we estimate the full timing-of-events model, starting from a two point distribution of unobservables. The first model indicates that there are significant positive in-treatment effects as well as post-treatment effects. ${ }^{11}$ After controlling for selection into temp employment the in-

11 The results are provided in Table B2, which will be available online. 
treatment effects declines considerably and the significant post-treatment effect disappears for men and becomes even significantly negative for women.

We proceed, next, by estimating the same model, allowing sequentially for extra mass points as described in section 4.1, freeing up the correlation structure of the unobservables. We add mass points as long as the Akaide Information Criterion improves (see, e.g., Gaure et al. 2007). It turns out that the in-treatment and post-treatment coefficients barely change after adding four mass points. The results after adding six support points, which is most often the optimal number, are in Table 2. We first report the treatment effects in the standard timing-ofevents model, where the duration of the treatment is taken as exogenous.

Table 2 shows that there are significant and high positive in-treatment effects, which means that currently working for a temp agency does significantly affect the transition rate to non-temp employment on average, when compared to a similar person in open unemployment. On the other hand, having worked for a temp agency at least once earlier in the same unemployment spell causes no significant increase in the hazard rate to ordinary employment for men. For women the post-treatment effect is significant and negative, lowering the exit rate by about 15 percent. ${ }^{12}$

It might be illustrative to compare the expected remaining unemployment durations for unemployed with and without treatment. To do so we follow the approach developed by Kyyrä et al. (2009) and calculate the expected remaining unemployment duration of entering a temp job at a given unemployment duration and at a given treatment duration, compared to the counterfactual of no treatment, i.e the average treatment effect on the treated. The median time until entry into the first temp job is about 11 weeks in our sample, and the median duration of a temp spell during an unemployment spell approximately 6 weeks. Performing this exercise, we find that the treatment reduces the expected remaining unemployment duration by about 4.6 weeks for men and 1.1 weeks for women. ${ }^{13}$

One might argue that the exit out of the treatment back into open unemployment might be endogenous as well. As outlined in Section 4, we extended the main model and jointly estimated the duration until a temp job, the duration of the treatment, and the unemployment duration, extending the distribution of unobservables to be trivariate.

12 As a robustness check, we run the model on the full sample with interaction terms for the excluded subgroups described in Section 5 and the treatment effects. It turns out the main conclusions do not change but that both, the coefficients of the lock-in effect and the post-treatment effect become slightly lower in size. Interestingly, the interaction terms of the post- and in-treatment effects with the nurses and the workers who are parallel assigned in formal education are negative. As described in Section 3, this result is expected because of the peculiar role the temporary help service industry plays in the health sector in Denmark and because students might not be interested in finding a regular job.

13 We considered in total 9 treatments by varying the time until entry into the first temp job and the duration of the temp jobs around the sample median. The results can be found in Table A3. 
Table A4 presents the full estimation results and shows that the selection into treatment and the hazard rate a quite similar to the main model. Regarding selection out of temporary agency employment back into open unemployment we find the following results: Young workers below the age of 24 have a much lower and workers above the age of 45 have a considerably higher transition rate than those between 25 and 44 . First generation male immigrants coming from non western countries have a much higher transition rate back into open unemployment. Interestingly, the transition probability for men decreases if the temp wage is higher. The number of previous treatments increase and the accumulated weeks of previous treatments decrease the transition probability for men and women.

Table 2, which summarizes the treatment effects, shows that the results are not considerably different from a standard timing-of-events model, implying that once the endogeneity of the treatment decision is taken into account, the additional endogeneity of the treatment duration does not appear to be very important. This indicates that selection out of the treatment does not give rise to large bias in the estimated parameters. We therefore continue in the remaining part of the paper without modeling explicitly the duration of the treatment as the computational burden increases considerably once one takes into account the endogeneity of the treatment duration.

\section{[Table 2 about here]}

Table 2 also presents results for the models with heterogeneous treatment effects, providing a deeper analysis of how in-treatment and post-treatment effects vary among unemployed job-seekers from different ethnic backgrounds, at different age, and for unemployed who were not eligible for unemployment benefits.

Turning first to the results on immigrant status, Table 2 shows that treated male, first generation, non-western immigrants, leave unemployment considerably faster than their untreated peers. The in-treatment effect is 48 percent larger than that of the natives and the posttreatment effect is 31 percent larger. Female immigrants have similarly large gains from treatment. While the post-treatment effects for native women is negative, all female immigrant groups also gain in terms of the post-treatment effect. The observation that temp employment is particularly effective for immigrants may be a consequence of employers having difficulties in observing the true productivity of workers with different ethnic backgrounds. Temporary agency employment seems to be a means to reduce information asymmetries for the employers and to overcome stigma effects for workers of different origin.

As for the age groups, we observe for all groups a positive in-treatment effect, increasing the exit rate to ordinary employment. However, the in-treatment effects are lower for older 
female workers, and for the group aged 20 to 24, which has just recently entered the labor market. Interestingly, male unemployed in this age group show a considerable high and significant positive post-treatment effect of around 13 percent. It might be that this group uses agency employment also to get to know potential employers and occupations before they finally accept a regular job. The results also reveal that the overall negative post-treatment effect for women is driven by the 'older' age groups (over 35 years of age)., while the posttreatment effect is close to zero for the age groups below 35 years of age.

Table 2 also shows the results for workers who are not eligible for unemployment insurance benefit and therefore receive the lower unemployment assistance: Both the in-treatments and post-treatment effects are significantly and considerably larger for this group of 'weaker' workers (as measured by their overall exit rate from unemployment). Interestingly, for unemployment assistance recipients the post-treatment effect is significantly positive. This holds for men (36 percent) and for women (30 percent). It seems that for this subgroup agency employment might be a means to free themselves from stigma effects which are usually attached to workers who are only eligible for unemployment assistance.

To sum up, the considerable positive in-treatment effects, in particular for the immigrants and the unemployment assistance recipients are an indication that firms use temp employment as a screening device in a tight labor market, where high-ability workers are costly to spot. In general, the post-treatment effects for women are negative, while they are not significant for men. However, it seems that the overall negative post-treatment effects for women are mainly driven by the age classes above 35 . It would certainly seem valid to conclude that temporary agency employment does no harm to the majority of unemployed workers, neither during nor after the temp job. Conversely, it seems that for most subgroups, temporary agency employment significantly reduces the remaining time spent in unemployment and thus serves as a stepping stone to employment. Only for women above the age of 35 is the evidence mixed in the sense that temporary agency work speeds up the transition into regular work while doing temp work, but reduces the transition rate into ordinary jobs after having received treatment.

\subsection{Effects of Treatment Intensity and Labor Market Tightness}

Proponents of the stepping-stone effect of agency work argue that job-seekers can improve their human capital while being on assignment, while critics point out that the human capital effect may be low. Whether human capital effects are responsible for the successful transition into employment cannot be tested directly. However, one way to approach this question is to investigate whether the cumulative duration of treatment, or the number of treatments earlier in the unemployment spell, affect the likelihood of finding ordinary employment. The number 
of treatments earlier in an unemployment spell may also serve as a proxy for the already mentioned network effects, as they can, at least theoretically, expand the worker's professional network.

Table 3 shows that the hazard rate into ordinary employment while in treatment increases with the total number of weeks in treatment in the past (during the current unemployment spell). This could suggest that there are indeed some human capital effects present which increase the likelihood of exiting unemployment to permanent jobs while being in treatment. However,the post-treatment hazards are not significant for men and are even negative for women, which might be taken as an indication that the accumulated human capital cannot be transferred to other employers.

[Table 3 about here]

Conditioning instead on the number of distinct temp job spells earlier in the unemployment spell reveals that the hazard rate into regular employment increases considerably for those who leave unemployment while being in treatment, except for women who experienced more than two treatments. However, the post-treatment effect is affected negatively by repeated treatments, implying perhaps low productivity or negative stigma effects. Again, this result may be taken as evidence for more firm or industry specific human capital which cannot be transferred. Moreover, it is likely that network effects do not play a large role for the stepping stone effect of agency employment.

Why is temporary agency work in Denmark a successful strategy for escaping unemployment, while it hardly works at all in other European countries? One explanation could be that the tightness of the Danish labor market is "responsible." As outlined in Section 3, the unemployment rate during our observation period was rather low. Consequently, firms had difficulties finding qualified workers. According to anecdotal evidence, there was competition between firms to find qualified workers, and firms even lured qualified workers away from competitors by offering fringe benefits. Therefore, it is plausible that agencies specialized in identifying job-seekers in the pool of unemployed in order to meet the staffing needs of user firms. User firms would then employ these workers first as temporary agency workers in order to screen them before hiring them into permanent positions. Despite the rather lax employment protection legislation in Denmark, this might be an optimal strategy, since it allows firms to avoid both large turnover costs and negative reputation effects if these workers do not prove to match the requirements or if demand declines.

In order to examine whether the treatment effect depends on labor market tightness or the business cycle, we included an interaction term in the basic model between the time-varying 
treatment indicators and the deviation of the local unemployment rate from the average unemployment rate of 5.9 during our observation period. The results are reported in Table 3.

Table 3 illustrates that there is indeed a significantly smaller in-treatment effect in regions and/or periods with above-average unemployment rates for men. An unemployment rate one percentage point above the average implies a 5 percent lower in-treatment effect. In addition, the post-treatment effect for men falls by about 2 percent if the regional unemployment rate is one percentage point above average. However, the coefficient is only significant at the 10 percent level (p-value: 0.06). For women the evidence is somewhat more mixed. A higher unemployment rate by one percentage point slightly increases the in-treatment effect and affects the post-treatment effect significantly negative. Overall, the stepping stone effect seems to be procyclical.

\subsection{Post-Unemployment Wages, Job Stability, and Employment Stability}

Despite the positive stepping-stone effects presented, one might worry that subsequent job quality, as measured by job or employment stability or by the level of hourly wages, is worse for the treated than for the untreated. One reason is that having held a temp job may be interpreted as a negative signal by prospective employers, causing them to offer lower wages or less stable jobs. In this section, we examine the effect of temporary agency employment on the quality of jobs found. In order to investigate the effect on post-unemployment wages, we specified a lognormal wage equation for the post-unemployment wage, as described in Section $4 .^{14}$

\section{[Table 4 about here]}

All variables included in the hazard rates were also included in the wage regressions. The results in the upper part of Table 4 show that only workers who exit directly into permanent employment while in treatment are able to increase their wages, while there is no significant effect for workers who find employment after treatment (the post-treatment effect). The results indicate that treated female workers receive wages that are on average 4 percent above the wages of comparable untreated workers. For men, the effect is even more pronounced: their jobs pay 6 percent more than those of the untreated. Presumably, this reflects, at least to some extent, a screening mechanism by which temps are hired into permanent jobs by the firms where they are 'temping'. As the client firm already knows the true productivity of the worker, theory would predict that the worker-job match is of higher quality and, consequent-

14 Employers report the gross earnings of their employees for the period the worker has been employed, but at least once a year. The wage refers to the average hourly wage during the notification period. Note that the data set does not report income of the unemployed that leave unemployment for self-employment. 
ly, that wages are higher for those who received a job offer during or directly after the temp job ended.

In a final step, we analyze the causal effect of having had a temporary agency employment spell during the unemployment spell on the subsequent job and employment duration. First, as a short-term indicator, we use the stability of the subsequent job immediately after leaving unemployment. As with post-unemployment wages, this variable again may be taken as an indicator of whether the match quality in the first job improves.

As a long-term outcome, we use, second, employment stability, measuring the number of weeks a person is employed after leaving unemployment, defined as the number of weeks employed without interruption after leaving successful unemployment - that is, unemployment terminating in a job offer. In this case, workers are allowed to switch jobs. ${ }^{15}$

Table 4 reports results from a set of models where the basic model is extended to include an additional equation for either subsequent employment or job duration. The results show that having had a temp job during unemployment has no impact on subsequent employment and job stability.

To sum up, those who find a job while in treatment increase their post-unemployment wages but post-unemployment job and employment durations are not affected by the treatment; that is, temp jobs tend to improve subsequent job quality in terms of wages and does not harm the workers in terms of job and employment stability.

\section{Conclusion}

The rapid growth of temporary agency employment in Denmark has led to doubts as to whether this form of employment is a desirable way of increasing labor market flexibility, as employment protection in Denmark is already low and flexibility is high. This holds the more as agency jobs do provide lower social and employment benefits than other jobs. Nevertheless, temporary agency work may have potential as a means of integrating workers who would otherwise have problems finding employment on their own. On the other hand, there is a risk that these are dead-end jobs. Answering this question for workers who enter agency employment after a period of unemployment is of special interest, since this group might be the most vulnerable with respect to their future employment prospects.

15 The employment career is considered as uninterrupted as long as there are no gaps lasting longer than three weeks. The reason for this decision is that there may be reporting gaps if a worker ends or starts a new job in the middle of the week. Moreover, the data reveal that reporting gaps increase during the summer vacation period. The likely reason is that workers with job changes during the summer often have a period of vacation typically lasting three weeks before they start a new job. As a robustness check, we allowed a reporting gap of only one week, which did not change the general results. 
We used and refined the timing-of-events model to estimate causal effects of temporary agency employment. First, we did not find any evidence of a lock-in effect. On the contrary, temporary agency employment speeds up the transition into permanent employment in the sense of reducing the remaining unemployment duration. The groups that benefit most from temporary agency employment are male first generation non-western immigrants, all female immigrant groups, and workers who were only eligible for unemployment assistance, groups which are usually considered hard to integrate into the labor market. Moreover, we found some, albeit weaker, evidence that the likelihood of exiting unemployment during treatment successfully increases with the duration of the treatment and to some extent with the number of treatments.

Why is temporary agency employment a successful path into regular employment for most groups in Denmark, when the evidence is much less promising in other European countries? The positive in-treatment effects found for groups that are often at risk of being excluded from the labor market due to stigma effects may indicate that employers facing labor shortages used temporary agency employment to screen candidates for permanent jobs. In a downturn, when the pool of highly qualified job-seekers swells again, employers might return to traditional (and cheaper) direct-hire strategies. To test this assumption, we investigated whether the stepping-stone effect depends on the tightness of the labor market. Our results indeed confirm that the stepping-stone effect reacts to the unemployment rate in a procyclical manner, i.e., the effects are more positive when unemployment is lower. We therefore believe that one reason for the positive stepping-stone effect of temporary agency employment in Denmark is the tight labor market during the observation period.

Even if temp work is be a bridge to regular employment, it is crucial to know what happens to the quality of a job match once a worker leaves unemployment. Research evidence on this question is of high policy relevance and entirely missing for continental Europe. A worsening of post-unemployment job quality would be a reason to be cautious about promoting temporary agency employment in an economy that is already highly flexible. However, our results suggest that unemployed job-seekers gain from taking temp jobs in terms of subsequent wages as well. The latter results may again support our assumption that the screening of workers may have played an important role for employers using agency workers.

As temporary agency employment has features of an ALMP instrument, the question naturally arises whether public employment offices should consider utilizing temporary help services more often as part of their overall job placement strategies. Denmark is spending about 2 percent of its GDP on ALMPs (OECD 2009). Despite these tremendous expenses, studies 
have generally shown that the effects of most activation programs are modest and sometimes even negative (e.g., Card et al. 2009). In Denmark, activation policies that involve some real working experience for unemployed workers, in particular employment subsidies in private firms, seem to be most effective (see, e.g., Kyyrä et al. 2009, Rosholm \& Svarer 2008, Jespersen et al. 2008). Almost all other program types show remarkably large lock-in effects. This may be a consequence of the fact that these instruments prolong benefit periods and discourage workers from searching for a regular job while in activation. Our findings suggest that temporary agency employment may be a useful alternative instrument of active labor market policy for some groups. This would offer an important source of cost savings since actively involving temporary agencies in the job placement strategies of the public employment service would come at almost no cost.

\section{References}

Abbring, J.; Van den Berg, G. (2003), "The Nonparametric Identification of Treatment Effects in Duration Models," Econometrica 71(5), 1491-1517.

Abraham, Katharine G. (1990), "Restructuring the employment relationship: The growth of market-mediated work arrangements." In Katharine G. Abraham and Robert B. McKersie, eds., New developments in the labour market: Toward a new institutional Paradigm. Cambridge, MA, MIT Press, pp. 85-119.

Amuedo-Dorantes, C.; Malo, M.; Muñoz-Bullón, F. (2008), "The Role of Temporary Help Agency Employment on Temp-to-Perm Transitions," Journal of Labor Research 29(2), $138-161$.

Andersson, F., Holzer, H. Lane, J., (2005). Moving Up or Moving On: Workers, Firms and Advancement in the Low-Wage Labor Market, New York: Russell Sage Foundation.

Andersson, F., Holzer, H., Lane J. (2009), “Temporary Help Agencies and the Advancement Prospects of Low Earners.” In David Autor, ed., Studies in Labor Market Intermediation, Chicago: The University of Chicago Press, 373-398.

Andersen, S. (2007), "Vikarer mellem fleksibilitet og sikkerhed,“" Tidsskrift for ARBEJDSliv, 9 (4), 63-78.

Antoni, M.; Jahn, E. (2009), "Do Changes in Regulation Affect Employment Duration in Temporary Work Agencies?” Industrial and Labor Relations Review 62(2), 226 - 251.

Arni, P.; Lalive, R.; van Ours, J. (2009), "How Effective Are Unemployment Benefit Sanctions? Looking Beyond Unemployment Exit”, IZA Discussion Papers 4509, Bonn.

Arrowsmith, J. (2008), "Temporary agency work and collective bargaining in the EU", European Foundation for the Improvement of Living and Working Conditions, Luxembourg.

Autor, D. (2009), "The Economics of Labor Market Intermediation: An Analytic Framework," In David Autor, ed., Studies in Labor Market Intermediation, Chicago: The University of Chicago Press, 1-23.

Autor, D.; Houseman, S. (2002), "The Role of Temporary Employment Agencies in Welfare to Work: Part of the Problem or Part of the Solution?" Focus 22(1), 63-70. 
(2005), "Do Temporary Help Jobs Improve Labor Market Outcomes for LowSkilled Workers? Evidence from Random Assignments,” NBER Working Paper No. 11743, forthcoming in: American Economic Journal: Applied Economics.

(2006), “Temporary Agency Employment as a Way out of Poverty?” In Rebecca Blank, Sheldon Danziger and Robert Schoeni, eds., Working but Poor: How Economic and Policy Changes are Affecting Low-Wage Workers, New York: Russell Sage.

Booth, A.; J. Francesconi, M.; J. Frank (2002), “Temporary Jobs: Stepping Stones or Dead Ends?" Economic Journal, 112, F189-F213.

Brinch, C. (2007), "Nonparametric Identification of the Mixed Hazards Model with TimeVarying Covariates", Econometric Theory, 23, 349-354.

CIETT (2002), "Rationale of Agency Work - European Labour Suppliers and Demanders' Motives to Engage in Agency Work," Rotterdam.

CIETT (2010), “Agency work indicators.” Online available: www.ciett.org.

Card, D.; J. Kluve; A. Weber (2009), "Active Labor Market Policy Evaluations: A MetaAnalysis," IZA Discussion Paper No. 4002, Bonn

Cockx, B.; Picchio, M. (2009), “Are Short-Lived Jobs Stepping Stones to Long-Lasting Jobs?” IZA Discussion Paper No. 4007, Bonn.

De Graaf-Zijl, M.; Van den Berg, G.; Hemya, A. (2010), "Stepping Stones for the Unemployed: The Effect of Temporary Jobs on the Duration until Regular Work," Journal of Population Economics, forthcoming.

Gagliarducci, S. (2005), "The dynamics of repeated temporary jobs," Labour Economics, 12, 429-448.

Gaure, S.; Roed, K.; Thang, T. (2007), "Time and causality: A Monte Carlo assessment of the timing of Events Approach," Journal of Econometrics 141(2), 1159-1195.

García-Pérez, J.; Muñoz-Bullón, F. (2005), Are Temporary Help Agencies Changing Mobility Patterns in the Spanish Labour Market?" Spanish Economic Review 7 (1), 43-65.

Göbel, Ch.; Verhofstadt, E. (2008), "Is Temporary Employment a Stepping Stone for Unemployed School Leavers?” ZEW Discussion Paper No. 08-093, Mannheim.

Hamersma, S.; Heinrich, C. (2008), “Temporary Help Service Firms' Use of Employer Tax Credits: Implications for Disadvantaged Workers' Labor Market Outcomes," Institute for Research on Poverty, Discussion paper 1335-08, Wisconsin.

Heckman, J.; LaLonde, R.; Smith, J. (1999), "The Economics and Econometrics of Active Labor Market Programs," in Handbook of Labor Economics, Vol: III, ed. by Ashenfelder, O.; Card, D., 1865-2097, Amsterdam.

Heckmann, J.; Singer, B. (1984), "A Method for Minimizing the Impact of Distributional Assumptions in Econometric Models for Duration Data," Econometrica, 52(2), 271-320.

Heinrich, C.; Mueser, P.; Troske, K. (2005): "Welfare to Temporary Work: Implications for Labor Market Outcomes," Review of Economics and Statistics 87(1), 154-173.

(2009), "The Role of Temporary Help Employment in Low-wage Worker Advancement." In David Autor, ed., Studies in Labor Market Intermediation, Chicago: The University of Chicago Press, 399-436.

Houseman, S; Kalleberg, A.; Erickcek, G. (2003), "The Role of Temporary Agency Employment in Tight Labor Markets," Industrial and Labor Relations Review 57(1), 105-127. 
Ichino, A.; Mealli, F; Nannicini, T. (2008), "From Temporary Help Jobs to Permanent Employment: What can we learn from matching estimators and their sensitivity?" Journal of Applied Econometrics, 23, 305-327.

Kudsk-Iversen, S; Andersen, S. (2006), I krydsfeltet mellem fleksibilitet og sikkerhed, Faos Discussion paper 071, Copenhagen, http://faos.sociology.ku.dk/dokum/fnotat71.pdf.

Jahn, E. (2010a), "Reassessing the wage penalty for temporary agency workers in Germany," Journal of Economics and Statistics, forthcoming.

Jahn, E. (2010b), "The structure of the temp wages in tight labor markets," mimeo.

Jahn, E.; Ochel, W. (2007), “Contracting-Out Temporary Help Services in Germany,” Journal of European Social Policy 17(2), 125-138.

Jensen, M.; Svarer, M.; Rosholm, M. (2003), “The Response of Youth Unemployment to Benefits, Incentives, and Sanctions,” European Journal of Political Economy 19, 301-316.

Jespersen, S., Munch, J.; Skipper, L. (2008), "Costs and benefits of Danish active labour market programmes," Labour Economics 15, 859-884.

Katz, L.; Krueger, A. (1999), “The High-Pressure U.S. Labor Market of the 1990s," Brookings Papers on Economic Activity 1, 1-65.

Kvasnicka, M. (2009), "Does Temporary Agency Work Provide a Stepping Stone to Regular Employment?" In David Autor, ed., Studies of Labor Market Intermediation, Chicago: The University of Chicago Press, 335-372.

Kyyrä T.; Parrotta, P.; Rosholm, M. (2009), "The effect of receiving supplementary UI benefits on unemployment duration," IZA Discussion Papers 3920, Bonn.

Lane, J.; Mikelson, K.; Sharkey, P.; Wissoker, D. (2003), "Pathways to Work for Low-Income Workers: The Effect of Work in the Temporary Help Industry," Journal of Policy Analysis and Management 22(4), 581-598.

Malo, M.; Muñoz-Bullón, F. (2008), "Temporary help agencies and participation histories in the labour market: a sequence-oriented approach," Estadística Española 50(167), 25- 65.

Mølgaard, J. and Hansen, L. (2008), "Vikarbeskæftigelsen fortsætter opad“, Arbejderbevægelsens Erhvervsråd, København, www.ae.dk/analyse/vikarbeskaeftigelsen-fortsaetter-opad.

OECD (2009), Employment Outlook, Paris.

Oxford Research (2003), "Nemme at hyre, nemme at fyre - undersøgelse af arbejdsforhold for vikarer i HK," Oxford Research, Copenhagen, 2003.

Pedersen, H.; Stener, H.; Claus, B.; Mahler, S. (2003), "Temporary Agency work in the European Union" (report), European Foundation for the Improvement of Living and Working Conditions, Dublin, http://www.fr.eurofound.eu.int/pubdocs/2004/104/en/1/ef04104en.pdf.

Rosholm, M.; Svarer, M. (2008), "Estimating the Threat Effect of Active Labour Market Programmes," Scandinavian Journal of Economics 110, 385-401.

Statistics Denmark (2009), "Produktstatistik for vikarbureauer og anden personaleformidling," 2007, København, http://www.dst.dk/pukora/epub/Nyt/2009/NR092.pdf.

Segal, L.; Sullivan, D. (1997), "The Growth of Temporary Services Work,” Journal of Economic Perspectives, 11, 117-136.

Windelin, M.; Hansen L. (2007), "Kraftigt stigende tendens til at bruge vikarer," Arbejderbevægelsens Erhvervsråd, http://www.ae.dk/analyse/kraftigt-stigende-tendens-tilbruge-vikarer, København. 


\section{Tables and Figures}

Table 1: Overview of events and outcomes

\begin{tabular}{|c|c|c|c|c|}
\hline & \multicolumn{2}{|c|}{ Men } & \multicolumn{2}{|c|}{ Women } \\
\hline & Treatment & Control & Treatment & Control \\
\hline Number of unemployment spells & 11,188 & 112,205 & 14,248 & 122,994 \\
\hline Number of persons & 3,822 & 31,811 & 5,556 & 34,441 \\
\hline Share right-censored spells & 2.83 & 4.07 & 2.92 & 3.86 \\
\hline Median unemployment duration in weeks & 33.00 & 10.00 & 32.00 & 9.00 \\
\hline Median duration of agency spell & 6.00 & & 5.00 & \\
\hline Median time until first accepting a temp job & 11.00 & & 10.00 & \\
\hline Mean number of agency spells & 1.43 & & 1.74 & \\
\hline Share of workers with more than one treatment & 24.75 & & 32.62 & \\
\hline $\begin{array}{l}\text { Percent of unemployment spells } \\
\text { ending in employment }\end{array}$ & 75.96 & 59.81 & 78.64 & 65.08 \\
\hline Mean wage before unemployment (DKK) & 122 & 129 & 121 & 122 \\
\hline Mean wage after unemployment (DKK) & 126 & 132 & 120 & 125 \\
\hline Median job stability in weeks (completed) & 22 & 11 & 32 & 7 \\
\hline Median employment stability in weeks (completed) & 36 & 25 & 52 & 14 \\
\hline
\end{tabular}

Fig 1: Smoothed Kaplan Meier hazard rates out of unemployment to employment and temp jobs
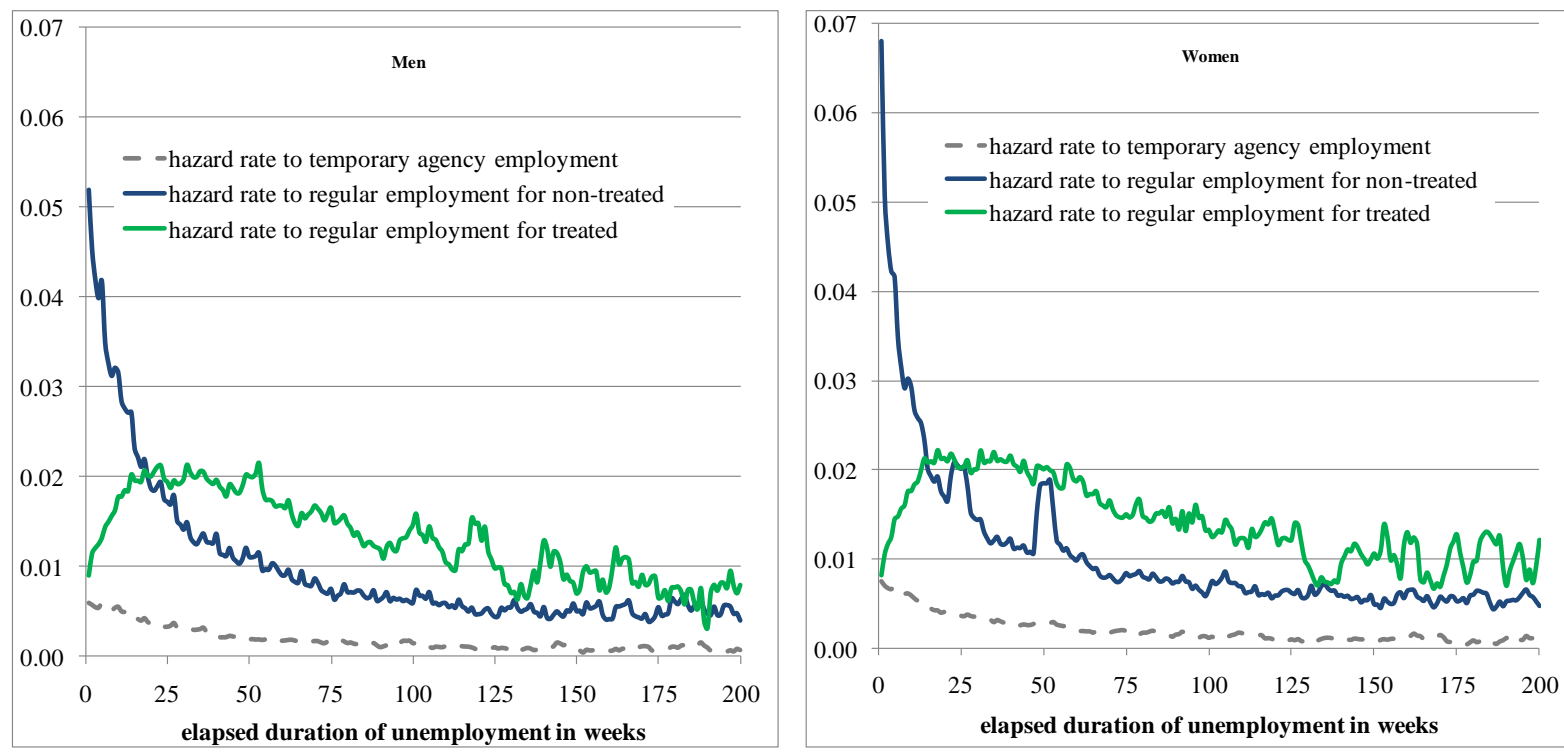
Table 2: Treatment effects

\begin{tabular}{|c|c|c|c|c|c|c|c|c|}
\hline & \multicolumn{4}{|c|}{ Men } & \multicolumn{4}{|c|}{ Women } \\
\hline & \multicolumn{2}{|c|}{ In-treatment } & \multicolumn{2}{|c|}{ Post-treatment } & \multicolumn{2}{|c|}{ In-treatment } & \multicolumn{2}{|c|}{ Post-treatment } \\
\hline & coef. & se & coef. & se & coef. & se & coef. & se \\
\hline \multicolumn{9}{|l|}{ Homogenous treatment effects } \\
\hline Exogenous treatment duration & 0.631 & $(0.014)$ & -0.015 & $(0.019)$ & 0.678 & $(0.013)$ & -0.150 & $(0.014)$ \\
\hline Mean log-likelihood & -2.715 & & & & -2.609 & & & \\
\hline Endogenous treatment duration & 0.598 & $(0.014)$ & 0.036 & $(0.020)$ & 0.655 & $(0.013)$ & -0.146 & $(0.015)$ \\
\hline Mean log-likelihood & -2.915 & & & & -2.910 & & & \\
\hline \multicolumn{9}{|l|}{ Heterogeneous treatment effects } \\
\hline \multicolumn{9}{|l|}{ Foreigner } \\
\hline Treatment (ref: natives) & 0.604 & $(0.015)$ & -0.024 & $(0.020)$ & 0.666 & $(0.013)$ & -0.171 & $(0.014)$ \\
\hline Treatment* west 1 st & 0.048 & $(0.077)$ & -0.074 & $(0.103)$ & 0.031 & $(0.077)$ & 0.214 & $(0.087)$ \\
\hline Treatment* west 2 nd & -0.001 & $(0.151)$ & 0.016 & $(0.291)$ & 0.328 & $(0.144)$ & 0.446 & $(0.210)$ \\
\hline Treatment* non west 1 st & 0.393 & $(0.058)$ & 0.268 & $(0.073)$ & $\mathbf{0 . 3 7 3}$ & $(0.088)$ & 0.438 & $(0.100)$ \\
\hline Treatment* non west 2 nd & 0.071 & $(0.138)$ & 0.060 & $(0.275)$ & 0.442 & $(0.163)$ & 0.460 & $(0.234)$ \\
\hline \multicolumn{9}{|l|}{ Age } \\
\hline Treatment (ref: $25<=$ age $<35$ ) & 0.665 & $(0.022)$ & 0.027 & $(0.030)$ & 0.798 & $(0.019)$ & -0.012 & $(0.025)$ \\
\hline Treatment $*$ age $<20$ & 0.086 & $(0.081)$ & 0.040 & $(0.120)$ & 0.060 & $(0.114)$ & 0.017 & $(0.159)$ \\
\hline Treatment $* 20<=$ age $<24$ & -0.123 & $(0.033)$ & 0.120 & $(0.049)$ & -0.112 & $(0.036)$ & 0.092 & $(0.049)$ \\
\hline Treatment $* 35<=$ age $<44$ & -0.024 & $(0.032)$ & -0.109 & $(0.048)$ & -0.115 & $(0.029)$ & -0.107 & $(0.035)$ \\
\hline Treatment $*$ age $>=45$ & -0.039 & $(0.036)$ & -0.160 & $(0.048)$ & -0.288 & $(0.029)$ & -0.371 & $(0.034)$ \\
\hline \multicolumn{9}{|l|}{ Unemployment Assistance } \\
\hline Treatment (ref: UB) & 0.560 & $(0.016)$ & -0.080 & $(0.021)$ & 0.641 & $(0.013)$ & -0.175 & $(0.015)$ \\
\hline Treatment*UA & 0.344 & $(0.031)$ & 0.387 & $(0.042)$ & 0.408 & $(0.035)$ & 0.441 & $(0.048)$ \\
\hline Number of unemployment spells & 11,188 & & 112,205 & & 14,248 & & 122,994 & \\
\hline
\end{tabular}

Notes: Bold coefficients are statistically significant at least at the 5 percent level. The distribution of the unobservables is approximated non-parametrically by a bivariate discrete distribution with six mass points. In addition, the model includes indicators for the year and quarter of entry into unemployment, for the number of temporary agency jobs $(1,2,3-4$, more than five), the number of regular jobs $(1,2,3-4$, more than five) during the past three years, indicators on how often the worker participated in programs of active labor market programs during the past three years (1, 2-3, more than 4), the yearly regional unemployment rate (based on 14 regions), dummy variable indicating whether the workers was previously out of the labor force, or sick, and parameters for the distribution of the unobserved characteristics. The model which takes the endogenous treatment duration explicitly into account in addition controls for wage received during the temp job, the number of previous treatments, and the accumulated number of weeks being treated. In this case the distribution of the unobservables is approximated by a trivariate discrete distribution with six mass points. 
Table 3: The effect of labor market tightness and repeated treatments

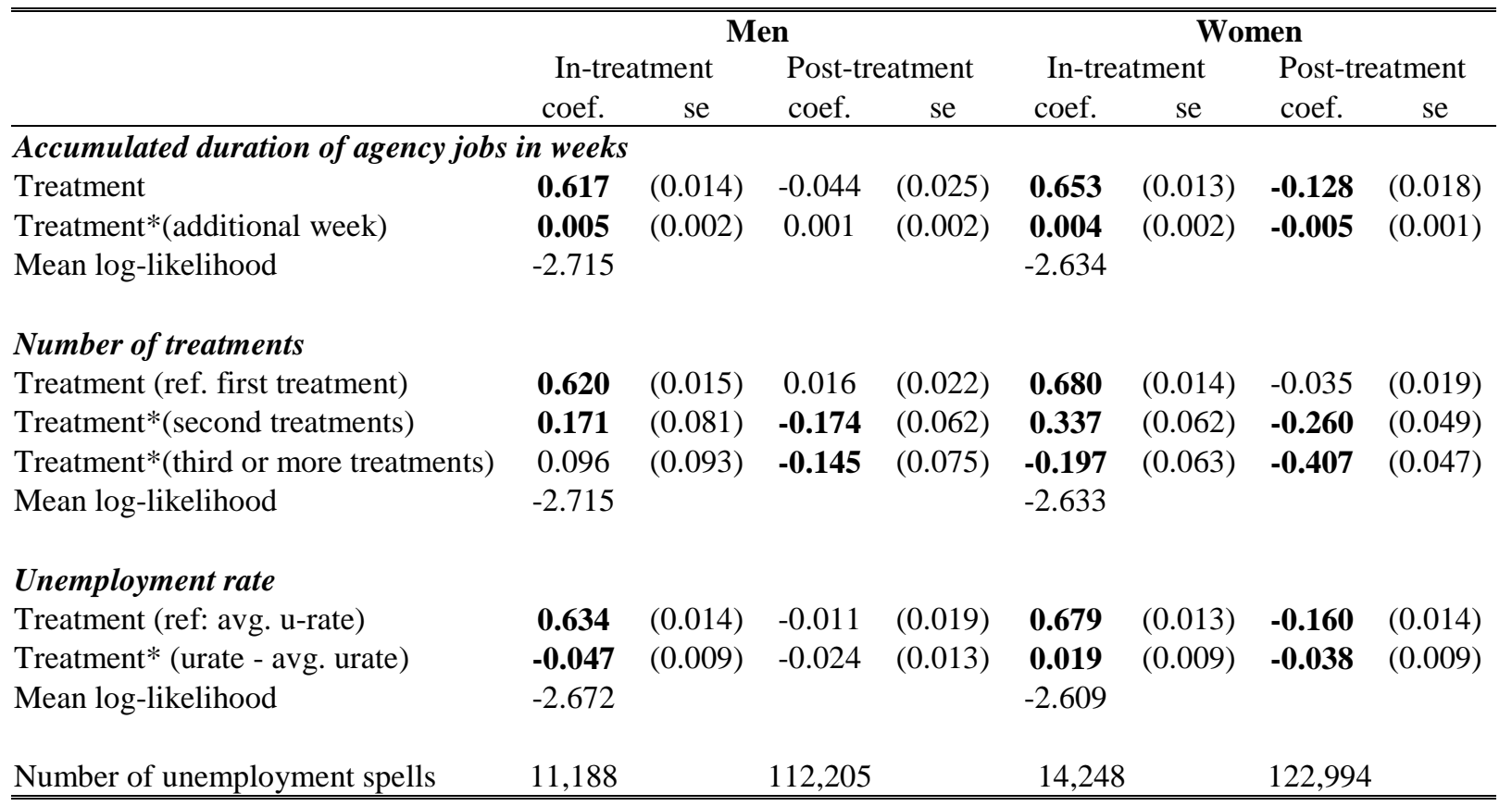

Notes: Bold coefficients are statistically significant at least at the 5 percent level. In addition the model includes the same controls as described in Table 2.

Table 4: Temporary agency employment and post-unemployment outcomes

\begin{tabular}{lccccccccc}
\hline \hline & \multicolumn{4}{c}{ Men } & \multicolumn{3}{c}{ Women } \\
& \multicolumn{2}{c}{ In-treatment } & \multicolumn{2}{c}{ Post-treatment } & \multicolumn{2}{c}{ In-treatment } & \multicolumn{2}{c}{$\begin{array}{c}\text { Post-treatment } \\
\text { coef. }\end{array}$} & se \\
\hline Wages & coef. & se & coef. & se & coef. & se & coef. \\
Mean log-likelihood & $\mathbf{0 . 0 6 6}$ & $(0.010)$ & 0.019 & $(0.012)$ & $\mathbf{0 . 0 4 6}$ & $(0.008)$ & 0.000 & $(0.009)$ \\
& -3.146 & & & & -3.018 & & & \\
Job stability & & & & & & & & \\
Mean log-likelihood & -0.017 & $(0.025)$ & -0.040 & $(0.035)$ & -0.023 & $(0.022)$ & -0.013 & $(0.028)$ \\
& -3.818 & & & & -3.749 & & & \\
Employment stability & -0.011 & $(0.027)$ & -0.032 & $(0.037)$ & -0.030 & $(0.023)$ & 0.011 & $(0.029)$ \\
Mean log-likelihood & -3.879 & & & & -3.791 & & & \\
Number of unemployment spells & 11,188 & & 112,205 & & 14,248 & & 122,994 \\
\hline \hline
\end{tabular}

Notes: Bold coefficients are statistically significant at least at the 5 percent level. The model includes the same controls as described in Table 2. The post-unemployment wages refer to the first wage immediately after leaving unemployment to a non temp job. Employment stability measures the total number of weeks employed without interruption and job stability measures the total number of weeks employed in the first job after leaving successful unemployment. 


\section{Appendix}

\section{Appendix A}

Table A1: Selected Sample Statistics

\begin{tabular}{|c|c|c|c|c|c|c|c|c|}
\hline & \multicolumn{4}{|c|}{ Men } & \multicolumn{4}{|c|}{ Women } \\
\hline & \multicolumn{2}{|c|}{ Treatment } & \multicolumn{2}{|c|}{ Control } & \multicolumn{2}{|c|}{ Treatment } & \multicolumn{2}{|c|}{ Control } \\
\hline & mean & sd & mean & sd & mean & sd & mean & sd \\
\hline \multicolumn{9}{|c|}{ Socio-economic characteristics } \\
\hline Single & 0.760 & 0.427 & 0.729 & 0.445 & 0.618 & 0.486 & 0.561 & 0.496 \\
\hline Working partner & 0.300 & 0.458 & 0.300 & 0.458 & 0.525 & 0.499 & 0.542 & 0.498 \\
\hline Child in household & 0.205 & 0.403 & 0.232 & 0.422 & 0.379 & 0.485 & 0.438 & 0.496 \\
\hline Child $<7$ in hh & 0.131 & 0.338 & 0.147 & 0.354 & 0.223 & 0.416 & 0.277 & 0.447 \\
\hline \multicolumn{9}{|l|}{ Age } \\
\hline Average & 33.4 & 10.6 & 34.4 & 11 & 36.3 & 10.6 & 37.3 & 11.2 \\
\hline Less than 20 & 0.032 & 0.176 & 0.031 & 0.172 & 0.013 & 0.113 & 0.018 & 0.132 \\
\hline $20-24$ & 0.223 & 0.416 & 0.183 & 0.387 & 0.129 & 0.336 & 0.109 & 0.312 \\
\hline $25-34$ & 0.345 & 0.476 & 0.359 & 0.480 & 0.354 & 0.478 & 0.341 & 0.474 \\
\hline $35-44$ & 0.212 & 0.409 & 0.221 & 0.415 & 0.251 & 0.434 & 0.247 & 0.431 \\
\hline Above 44 & 0.188 & 0.390 & 0.206 & 0.405 & 0.253 & 0.435 & 0.284 & 0.451 \\
\hline \multicolumn{9}{|l|}{ Nationality } \\
\hline Danish & 0.902 & 0.298 & 0.887 & 0.316 & 0.948 & 0.223 & 0.928 & 0.259 \\
\hline 1 st gen. west & 0.028 & 0.165 & 0.025 & 0.157 & 0.024 & 0.152 & 0.021 & 0.143 \\
\hline 2nd gen. west & 0.004 & 0.065 & 0.004 & 0.064 & 0.003 & 0.058 & 0.004 & 0.060 \\
\hline 1 st gen. non west & 0.058 & 0.234 & 0.075 & 0.263 & 0.020 & 0.141 & 0.041 & 0.199 \\
\hline 2nd gen non west & 0.008 & 0.089 & 0.009 & 0.094 & 0.005 & 0.070 & 0.006 & 0.079 \\
\hline \multicolumn{9}{|l|}{ Education } \\
\hline Low & 0.498 & 0.500 & 0.527 & 0.499 & 0.374 & 0.484 & 0.455 & 0.498 \\
\hline Vocational training & 0.403 & 0.490 & 0.382 & 0.486 & 0.434 & 0.496 & 0.377 & 0.485 \\
\hline Short academic & 0.055 & 0.228 & 0.040 & 0.195 & 0.089 & 0.284 & 0.059 & 0.236 \\
\hline Bachelor & 0.031 & 0.173 & 0.034 & 0.181 & 0.075 & 0.264 & 0.084 & 0.277 \\
\hline Master & 0.013 & 0.114 & 0.018 & 0.133 & 0.029 & 0.167 & 0.025 & 0.157 \\
\hline Copenhagen & 0.292 & 0.455 & 0.264 & 0.441 & 0.363 & 0.481 & 0.279 & 0.448 \\
\hline \multicolumn{9}{|l|}{ Prev. LF status } \\
\hline Employed & 0.363 & 0.481 & 0.494 & 0.500 & 0.375 & 0.484 & 0.530 & 0.499 \\
\hline Temp employed & 0.266 & 0.442 & 0.027 & 0.161 & 0.248 & 0.432 & 0.020 & 0.139 \\
\hline Self-employed & 0.004 & 0.063 & 0.010 & 0.099 & 0.001 & 0.034 & 0.006 & 0.077 \\
\hline Sick & 0.072 & 0.258 & 0.066 & 0.248 & 0.082 & 0.275 & 0.071 & 0.257 \\
\hline Out of labor force & 0.296 & 0.456 & 0.404 & 0.491 & 0.294 & 0.455 & 0.373 & 0.484 \\
\hline \multicolumn{9}{|l|}{ Employment history } \\
\hline Empl. dur (weeks) & 75.1 & 52.2 & 74.3 & 52.3 & 78.5 & 52.0 & 70.3 & 49.5 \\
\hline Avg. no. temp jobs & 0.755 & 1.290 & 0.405 & 0.948 & 0.818 & 1.610 & 0.485 & 1.420 \\
\hline Avg. no. almp & 0.585 & 1.200 & 0.596 & 1.190 & 0.539 & 1.100 & 0.632 & 1.190 \\
\hline Avg. no. reg. jobs & 2.860 & 2.380 & 3.300 & 3.220 & 2.610 & 2.430 & 3.930 & 4.710 \\
\hline Unemployment assistance & 0.273 & 0.446 & 0.291 & 0.454 & 0.121 & 0.326 & 0.163 & 0.369 \\
\hline No. of persons & 3,822 & & 31,811 & & 5,556 & & 34,441 & \\
\hline No. of u-spells & 11,188 & & 112,205 & & 14,248 & & 122,994 & \\
\hline
\end{tabular}

Notes: Pre-wages refer to the average hourly wage in DKK of the job before entering unemployment; postwages refer to the first job after leaving successful unemployment. Employment stability measures the median total number of weeks employed and job stability measures the median number of weeks employed in the first job after leaving successful unemployment. 
Table A2: Full estimation results - homogenous treatment effects - main model

\begin{tabular}{|c|c|c|c|c|c|c|c|c|c|}
\hline & & \multicolumn{4}{|c|}{ Men } & \multicolumn{4}{|c|}{ Women } \\
\hline & & \multicolumn{2}{|c|}{ sel. equation } & \multicolumn{2}{|c|}{ hazard to empl. } & \multicolumn{2}{|c|}{ sel. equation } & \multicolumn{2}{|c|}{ hazard to empl. } \\
\hline & & coef. & se & coef. & se & coef. & se & coef & se \\
\hline \multirow{12}{*}{$\begin{array}{l}\text { Baseline hazard } \\
\text { (weeks) }\end{array}$} & $0-4$ & -5.383 & $(0.154)$ & -2.561 & $(0.093)$ & -4.499 & $(0.111)$ & -2.604 & $(0.053)$ \\
\hline & $4-8$ & -5.150 & $(0.155)$ & -2.486 & $(0.094)$ & -4.383 & $(0.112)$ & -2.836 & $(0.054)$ \\
\hline & $8-12$ & -5.096 & $(0.156)$ & -2.607 & $(0.094)$ & -4.327 & $(0.113)$ & -3.059 & $(0.054)$ \\
\hline & $12-16$ & -5.024 & $(0.157)$ & -2.603 & $(0.094)$ & -4.332 & $(0.114)$ & -3.028 & $(0.055)$ \\
\hline & $16-20$ & -5.150 & $(0.158)$ & -2.727 & $(0.095)$ & -4.459 & $(0.116)$ & -3.217 & $(0.055)$ \\
\hline & $20-25$ & -5.265 & $(0.160)$ & -2.820 & $(0.095)$ & -4.462 & $(0.117)$ & -3.294 & $(0.055)$ \\
\hline & $25-35$ & -5.214 & $(0.159)$ & -2.830 & $(0.095)$ & -4.478 & $(0.116)$ & -3.147 & $(0.055)$ \\
\hline & $35-52$ & -5.390 & $(0.160)$ & -2.957 & $(0.094)$ & -4.603 & $(0.117)$ & -3.304 & $(0.055)$ \\
\hline & $52-78$ & -5.636 & $(0.163)$ & -3.040 & $(0.095)$ & -4.818 & $(0.119)$ & -3.351 & $(0.055)$ \\
\hline & $78-104$ & -5.755 & $(0.168)$ & -3.157 & $(0.096)$ & -5.039 & $(0.127)$ & -3.459 & $(0.058)$ \\
\hline & $104-156$ & -6.140 & $(0.174)$ & -3.327 & $(0.097)$ & -5.254 & $(0.130)$ & -3.592 & $(0.058)$ \\
\hline & -156 & -6.276 & $(0.182)$ & -3.419 & $(0.099)$ & -5.476 & $(0.142)$ & -3.702 & $(0.062)$ \\
\hline \multirow[t]{4}{*}{ Age (ref: 25-34) } & less than 20 & 0.482 & $(0.063)$ & 0.215 & $(0.030)$ & 0.160 & $(0.083)$ & 0.175 & $(0.038)$ \\
\hline & $20-24$ & 0.427 & $(0.030)$ & 0.257 & $(0.012)$ & 0.253 & $(0.032)$ & 0.201 & $(0.014)$ \\
\hline & $35-44$ & 0.003 & $(0.029)$ & -0.089 & $(0.011)$ & -0.021 & $(0.026)$ & -0.059 & $(0.011)$ \\
\hline & above 44 & -0.100 & $(0.033)$ & -0.254 & $(0.013)$ & -0.146 & $(0.028)$ & -0.157 & $(0.012)$ \\
\hline \multirow{4}{*}{$\begin{array}{l}\text { Family status } \\
\text { (ref: no working } \\
\text { partner) }\end{array}$} & Single & 0.032 & $(0.030)$ & -0.066 & $(0.011)$ & 0.034 & $(0.023)$ & -0.037 & $(0.010)$ \\
\hline & Working partner & 0.194 & $(0.026)$ & 0.143 & $(0.010)$ & 0.079 & $(0.021)$ & 0.092 & $(0.008)$ \\
\hline & Child in hh & -0.030 & $(0.043)$ & 0.143 & $(0.015)$ & -0.101 & $(0.029)$ & 0.041 & $(0.011)$ \\
\hline & Child $<7$ in hh & -0.051 & $(0.048)$ & -0.123 & $(0.017)$ & -0.252 & $(0.032)$ & -0.095 & $(0.012)$ \\
\hline \multirow{4}{*}{$\begin{array}{l}\text { Nationality } \\
\text { (ref: natives) }\end{array}$} & 1st gen. west & 0.048 & $(0.066)$ & -0.100 & $(0.030)$ & -0.049 & $(0.062)$ & -0.124 & $(0.033)$ \\
\hline & 2nd gen. west & 0.063 & $(0.169)$ & -0.115 & $(0.079)$ & -0.092 & $(0.162)$ & 0.085 & $(0.081)$ \\
\hline & 1st gen. non west & -0.367 & $(0.048)$ & -0.242 & $(0.021)$ & -0.635 & $(0.064)$ & -0.283 & $(0.026)$ \\
\hline & 2nd gen non west & -0.302 & $(0.119)$ & -0.080 & $(0.061)$ & -0.549 & $(0.137)$ & -0.264 & $(0.072)$ \\
\hline \multirow{4}{*}{$\begin{array}{l}\text { Education } \\
\text { (ref: low) }\end{array}$} & Voc. training & 0.189 & $(0.026)$ & 0.159 & $(0.011)$ & 0.187 & $(0.023)$ & 0.093 & $(0.010)$ \\
\hline & Short academic & 0.402 & $(0.053)$ & 0.173 & $(0.023)$ & 0.294 & $(0.039)$ & 0.131 & $(0.020)$ \\
\hline & Bachelor & 0.134 & $(0.066)$ & 0.266 & $(0.027)$ & 0.006 & $(0.041)$ & 0.246 & $(0.018)$ \\
\hline & Master & -0.178 & $(0.108)$ & 0.111 & $(0.040)$ & -0.124 & $(0.071)$ & 0.202 & $(0.036)$ \\
\hline Empl. dur. (weeks) & & 0.224 & $(0.043)$ & 0.128 & $(0.016)$ & 0.391 & $(0.038)$ & -0.188 & $(0.014)$ \\
\hline Capital & & 0.092 & $(0.028)$ & -0.071 & $(0.012)$ & 0.144 & $(0.022)$ & 0.002 & $(0.011)$ \\
\hline UI-funds & No membership & -0.598 & $(0.032)$ & -0.548 & $(0.013)$ & -0.714 & $(0.039)$ & -0.479 & $(0.016)$ \\
\hline \multirow[t]{8}{*}{ (ref: manuf.) } & Construction & 0.004 & $(0.046)$ & 0.158 & $(0.017)$ & -0.259 & $(0.129)$ & 0.051 & $(0.043)$ \\
\hline & Technicans & -0.183 & $(0.057)$ & -0.157 & $(0.022)$ & 0.003 & $(0.057)$ & -0.045 & $(0.024)$ \\
\hline & White collar & -0.171 & $(0.065)$ & -0.195 & $(0.025)$ & 0.046 & $(0.040)$ & 0.125 & $(0.016)$ \\
\hline & Academics & -0.225 & $(0.090)$ & -0.222 & $(0.038)$ & 0.325 & $(0.056)$ & -0.099 & $(0.028)$ \\
\hline & Others & -0.143 & $(0.040)$ & -0.097 & $(0.014)$ & -0.103 & $(0.034)$ & 0.094 & $(0.012)$ \\
\hline & Self-employed & -0.661 & $(0.112)$ & -0.185 & $(0.034)$ & -0.665 & $(0.114)$ & -0.041 & $(0.033)$ \\
\hline & Metal Industry & 0.185 & $(0.039)$ & 0.001 & $(0.016)$ & 0.035 & $(0.201)$ & -0.149 & $(0.096)$ \\
\hline & Trade & 0.139 & $(0.045)$ & -0.295 & $(0.022)$ & 0.267 & $(0.032)$ & -0.025 & $(0.013)$ \\
\hline \multirow[t]{2}{*}{ Treatment effect } & In-treatment & & & 0.631 & $(0.014)$ & & & 0.678 & $(0.013)$ \\
\hline & Post-treatment & & & -0.015 & $(0.019)$ & & & -0.150 & $(0.014)$ \\
\hline \multicolumn{2}{|l|}{ Mean log- } & \multicolumn{4}{|c|}{-2.715} & \multicolumn{4}{|c|}{-2.634} \\
\hline \multicolumn{2}{|l|}{$\begin{array}{l}\text { likelihood } \\
\text { No. of u-spells }\end{array}$} & \multicolumn{4}{|c|}{123,393} & \multicolumn{4}{|c|}{137,242} \\
\hline
\end{tabular}

Notes: Bold coefficients are statistically significant at least at the 5 percent level. The model includes the same controls as described in Table 2. Results for further controls are available upon request. 
Table A3 Expected remaining unemployment duration

\begin{tabular}{ll|rrr|rcc}
\hline \hline & & \multicolumn{3}{|c|}{ Men } & \multicolumn{3}{c}{ Women } \\
\multicolumn{1}{c}{$\boldsymbol{t}_{\boldsymbol{p}}$} & $\boldsymbol{t}_{\boldsymbol{d}}$ & $\boldsymbol{T}_{\boldsymbol{p}}=\infty$ & $\boldsymbol{T}_{\boldsymbol{p}}=\boldsymbol{t}_{\boldsymbol{p}}$ & $\boldsymbol{\Psi}\left(\boldsymbol{t}_{\boldsymbol{p}}, \boldsymbol{t}_{\boldsymbol{d}}\right)$ & $\boldsymbol{T}_{\boldsymbol{p}}=\infty$ & $\boldsymbol{T}_{\boldsymbol{p}}=\boldsymbol{t}_{\boldsymbol{p}}$ & $\boldsymbol{\Psi}\left(\boldsymbol{t}_{\boldsymbol{p}}, \boldsymbol{t}_{\boldsymbol{d}}\right)$ \\
\hline 4 & 2 & 22.51 & 20.92 & -1.59 & 33.27 & 36.09 & 2.82 \\
4 & 6 & 22.51 & 17.99 & -4.52 & 33.27 & 31.12 & -2.15 \\
4 & 12 & 22.51 & 15.47 & -7.04 & 33.27 & 26.60 & -6.67 \\
\hline 11 & 2 & 24.53 & 22.93 & -1.60 & 36.37 & 40.24 & 3.87 \\
11 & 6 & 24.53 & 19.89 & -4.64 & 36.37 & 35.25 & -1.12 \\
11 & 12 & 24.53 & 17.34 & -7.19 & 36.37 & 30.83 & -5.54 \\
\hline 26 & 2 & 27.97 & 26.53 & -1.44 & 38.73 & 42.97 & 4.24 \\
26 & 6 & 27.97 & 23.57 & -4.40 & 38.73 & 38.15 & -0.58 \\
26 & 12 & 27.97 & 20.66 & -7.31 & 38.73 & 33.06 & -5.67 \\
\hline \hline
\end{tabular}

Notes: $t_{p}$ denotes the realized timing of the treatment, i.e. the time until entry into temp employment, and $\Delta$ is the duration of the temp job. $\Psi\left(t_{p}, \boldsymbol{t}_{\boldsymbol{d}}\right)$ measures the effect on the remaining unemployment duration of entering temp employment at unemployment duration $t_{p}$ and staying there for (at most) $\Delta$ weeks, compared to the counterfactual of no treatment, see Kyyrä et al. (2009). 
Table A4: Full estimation results - homogenous treatment effects - endogeneity of treatment duration

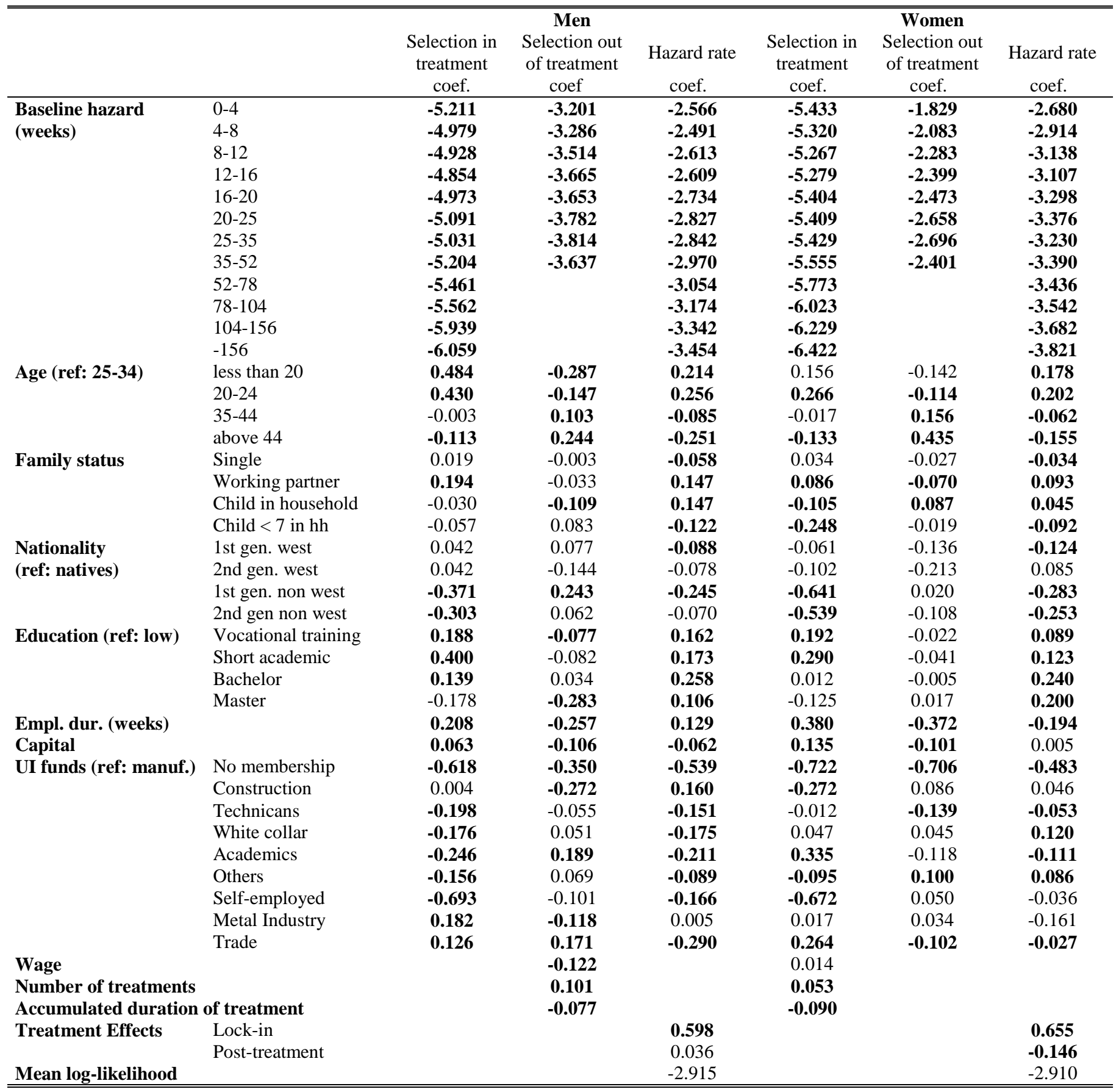

Notes: Bold coefficients are statistically significant at least at the 5 percent level. The model includes the same controls as described in Table 2. Results for further controls are available upon request. 


\section{Appendix B (not for publication)}

Table B1: Sample selection (unemployment spells)

\begin{tabular}{|c|c|c|c|c|c|c|c|c|}
\hline & \multicolumn{4}{|c|}{ Men } & \multicolumn{4}{|c|}{ Women } \\
\hline & \multicolumn{2}{|c|}{$\begin{array}{l}\text { Control } \\
\text { in } \%\end{array}$} & \multicolumn{2}{|c|}{$\begin{array}{l}\text { Treatment } \\
\text { in } \% \\
\end{array}$} & \multicolumn{2}{|c|}{$\begin{array}{l}\text { Control } \\
\text { in } \%\end{array}$} & \multicolumn{2}{|c|}{$\begin{array}{l}\text { Treatment } \\
\text { in } \%\end{array}$} \\
\hline Full Sample & 128,547 & 100.0 & 14,038 & 100.0 & 163,569 & 100.0 & 19,524 & 100.0 \\
\hline - Management & 11,350 & 8.8 & 1,029 & 7.3 & 18,641 & 11.4 & 1,533 & 7.9 \\
\hline - Health sector & 1,342 & 1.0 & 162 & 1.2 & 17,989 & 11.0 & 1,933 & 9.9 \\
\hline - Parallel student & 3,650 & 2.8 & 942 & 6.7 & 3,945 & 2.4 & 882 & 4.5 \\
\hline - Spell over 52 weeks & 0 & 0.0 & 658 & 4.7 & 0 & 0.0 & 855 & 4.4 \\
\hline - Public sector temp & 0 & 0.0 & 59 & 0.4 & 0 & 0.0 & 73 & 0.4 \\
\hline Final data set & 112,205 & 87.3 & 11,188 & 79.7 & 122,994 & 75.2 & 14,248 & 73.0 \\
\hline
\end{tabular}

Table B2: Homogenous treatment effects - baseline estimations

\begin{tabular}{|c|c|c|c|c|c|c|c|c|}
\hline & \multicolumn{2}{|c|}{ Model 1} & \multicolumn{2}{|c|}{ Model 2} & \multicolumn{2}{|c|}{ Model 3} & \multicolumn{2}{|c|}{ Model 4} \\
\hline & coef. & se & coef. & se & coef. & se & coef. & se \\
\hline \multicolumn{9}{|l|}{ Men } \\
\hline In-treatment & 0.859 & $(0.013)$ & 0.592 & $(0.012)$ & 0.639 & $(0.013)$ & 0.624 & $(0.014)$ \\
\hline Post-treatment & 0.272 & $(0.019)$ & 0.010 & $(0.017)$ & 0.024 & $(0.017)$ & -0.014 & $(0.019)$ \\
\hline Unobserved heterogeneity & no & & no & & yes & & yes & \\
\hline Control variables & no & & yes & & yes & & yes & \\
\hline Mass points & - & & - & & 2 & & 5 & \\
\hline Log-Likelihood & -2.417 & & -2.270 & & -2.721 & & -2.715 & \\
\hline $\mathrm{N}$ & 146,877 & & 146,877 & & 146,877 & & 146,877 & \\
\hline \multicolumn{9}{|l|}{ Women } \\
\hline In-treatment & 0.856 & $(0.013)$ & 0.653 & $(0.011)$ & 0.719 & $(0.012)$ & 0.675 & $(0.013)$ \\
\hline Post-treatment & 0.227 & $(0.016)$ & -0.108 & $(0.014)$ & -0.107 & $(0.013)$ & -0.153 & $(0.014)$ \\
\hline Unobserved heterogeneity & no & & no & & yes & & yes & \\
\hline Control variables & no & & yes & & yes & & yes & \\
\hline Mass-points & - & & - & & 2 & & 5 & \\
\hline Mean log-likelihood & -2.333 & & -2.185 & & -2.640 & & -2.634 & \\
\hline $\mathrm{N}$ & 176,314 & & 176,314 & & 176,314 & & 176,314 & \\
\hline
\end{tabular}

Notes: Bold coefficients are statistically significant at least at the 5 percent level. The model includes the same controls as described in Table 2. 
Table B3: Heterogeneous treatment effects - further subgroups

\begin{tabular}{|c|c|c|c|c|c|c|c|c|}
\hline & \multicolumn{4}{|c|}{ Men } & \multicolumn{4}{|c|}{ Women } \\
\hline & \multicolumn{2}{|c|}{ In-treatment } & \multicolumn{2}{|c|}{ Post-treatment } & \multicolumn{2}{|c|}{ In-treatment } & \multicolumn{2}{|c|}{ Post-treatment } \\
\hline & coef. & se & coef. & se & coef. & se & coef. & se \\
\hline \multicolumn{9}{|l|}{ Education (edu) } \\
\hline Treatment (ref: low edu) & 0.748 & $(0.019)$ & -0.012 & $(0.025)$ & 0.712 & $(0.020)$ & -0.196 & $(0.021)$ \\
\hline Treatment*vocational edu & -0.263 & $(0.026)$ & 0.014 & $(0.037)$ & -0.055 & $(0.025)$ & 0.034 & $(0.028)$ \\
\hline Treatment*short academic edu & -0.084 & $(0.056)$ & 0.044 & $(0.083)$ & 0.057 & $(0.041)$ & 0.174 & $(0.049)$ \\
\hline Treatment*medium academic edu & -0.078 & $(0.072)$ & -0.048 & $(0.089)$ & -0.242 & $(0.044)$ & 0.069 & $(0.057)$ \\
\hline Treatment*long academic edu & 0.113 & $(0.128)$ & 0.092 & $(0.173)$ & 0.036 & $(0.073)$ & 0.169 & $(0.092)$ \\
\hline \multicolumn{9}{|l|}{ Family Status } \\
\hline Treatment (ref: married $*$ no child) & 0.634 & $(0.030)$ & -0.035 & $(0.041)$ & $\mathbf{0 . 5 3 0}$ & $(0.023)$ & -0.267 & $(0.024)$ \\
\hline Treatment*married $*$ child & -0.012 & $(0.051)$ & -0.129 & $(0.076)$ & 0.328 & $(0.038)$ & 0.282 & $(0.043)$ \\
\hline Treatment*single*no child & -0.016 & $(0.033)$ & 0.043 & $(0.046)$ & 0.130 & $(0.027)$ & 0.144 & $(0.030)$ \\
\hline Treatment*single* child & 0.063 & $(0.054)$ & 0.113 & $(0.079)$ & 0.431 & $(0.042)$ & 0.213 & $(0.054)$ \\
\hline \multicolumn{9}{|l|}{ Working Partner } \\
\hline Treatment (ref: no) & 0.662 & $(0.016)$ & 0.007 & $(0.022)$ & 0.700 & $(0.018)$ & -0.147 & $(0.020)$ \\
\hline Treatment* yes & -0.114 & $(0.026)$ & -0.061 & $(0.038)$ & -0.050 & $(0.022)$ & -0.032 & $(0.026)$ \\
\hline \multicolumn{9}{|l|}{ Employment Experience (weeks) } \\
\hline Treatment (ref: no employment) & 0.577 & $(0.024)$ & -0.004 & $(0.031)$ & 0.592 & $(0.022)$ & -0.229 & $(0.024)$ \\
\hline Treatment* $0<$ empex $<=52 \mathrm{r}$ & 0.867 & $(0.050)$ & 0.279 & $(0.068)$ & 0.833 & $(0.045)$ & $\mathbf{0 . 3 7 7}$ & $(0.052)$ \\
\hline Treatment $* 52<$ empdex $<=104$ & 0.160 & $(0.033)$ & -0.003 & $(0.045)$ & 0.096 & $(0.031)$ & -0.067 & $(0.034)$ \\
\hline Treatment $* 104<$ empex & -0.113 & $(0.030)$ & -0.089 & $(0.044)$ & 0.010 & $(0.028)$ & 0.181 & $(0.033)$ \\
\hline
\end{tabular}

Notes: Bold coefficients are statistically significant at least at the 5 percent level In addition the model includes the same controls as described in Table 2. 